\title{
Cross-modal reaction of auditory and visual cortices after long-term bilateral hearing deprivation in the rat
}

\author{
M. Pernia ${ }^{1}$ - I. Díaz ${ }^{1}$ - A. C. Colmenárez-Raga ${ }^{1} \cdot$ C. Rivadulla ${ }^{2} \cdot$ J. Cudeiro $^{2} \cdot$ I. Plaza $^{1} \cdot$ M. A. Merchán ${ }^{10}$
}

Received: 20 April 2019 / Accepted: 21 November 2019 / Published online: 28 November 2019

(c) The Author(s) 2019

\begin{abstract}
Visual cortex (VC) over-activation analysed by evoked responses has been demonstrated in congenital deafness and after longterm acquired hearing loss in humans. However, permanent hearing deprivation has not yet been explored in animal models. Thus, the present study aimed to examine functional and molecular changes underlying the visual and auditory cross-modal reaction. For such purpose, we analysed cortical visual evoked potentials (VEPs) and the gene expression (RT-qPCR) of a set of markers for neuronal activation (c-Fos) and activity-dependent homeostatic compensation (Arc/Arg3.1). To determine the state of excitation and inhibition, we performed RT-qPCR and quantitative immunocytochemistry for excitatory (receptor subunits GluA2/3) and inhibitory (GABAA- $\alpha 1$, GABAB-R2, GAD65/67 and parvalbumin-PV) markers. VC over-activation was demonstrated by a significant increase in VEPs wave $\mathrm{N} 1$ and by up-regulation of the activity-dependent early genes c-Fos and Arc/Arg3.1 (thus confirming, by RT-qPCR, our previously published immunocytochemical results). GluA2 gene and protein expression were significantly increased in the auditory cortex (AC), particularly in layers $2 / 3$ pyramidal neurons, but inhibitory markers (GAD65/67 and PV-GABA interneurons) were also significantly upregulated in the AC, indicating a concurrent increase in inhibition. Therefore, after permanent hearing loss in the rat, the VC is not only over-activated but also potentially balanced by homeostatic regulation, while excitatory and inhibitory markers remain imbalanced in the AC, most likely resulting from changes in horizontal intermodal regulation.
\end{abstract}

Keywords Visual evoked potentials · RT-qPCR · Quantitative immunocytochemistry · GluA2/3 (RRID: AB_90710) · GAD 67 (RRID: AB_2278725) · Parvalbumin (AB_10000344)

$\begin{array}{ll}\text { Abbreviations } \\ \text { ABRs } & \text { Auditory brainstem recordings } \\ \text { AC } & \text { Auditory cortex } \\ \text { AC1 } & \text { Primary auditory cortex } \\ \text { ACD } & \text { Dorsal auditory cortex } \\ \text { ACV } & \text { Ventral auditory cortex } \\ \text { AMPA Rs } & \text { AMPA receptors } \\ \text { dpl } & \text { Days post-lesion } \\ \text { FS } & \text { Fast-spiking } \\ \text { FS-PV } & \text { Fast-spiking parvalbumin } \\ \text { IA } & \text { Interaural }\end{array}$

M. A. Merchán merchan@usal.es

1 Instituto de Neurociencias of Castilla y León-INCyL, Universidad de Salamanca, Salamanca, Spain

2 Centro de Investigaciones Científicas Avanzadas (CICA), Facultad de Ciencias de la Salud, Universidad de A Coruña and Instituto de Investigaciones Biomédicas de A Coruña (INIBIC), A Coruña, Spain

$\begin{array}{ll}\text { OD } & \text { Optical density } \\ \text { PB } & \text { Phosphate buffer } \\ \text { PtPD } & \text { Parietal postero-dorsal cortex } \\ \text { PtPR } & \text { Parietal postero-rostral cortex } \\ \text { PV } & \text { Parvalbumin } \\ \text { SSC } & \text { Somatosensory cortex } \\ \text { TBS-Tx } & \text { Tris-Buffered saline }+0.5 \% \text { Triton X-100 } \\ \text { VC } & \text { Visual cortex } \\ \text { VC1 } & \text { Primary visual cortex } \\ \text { V2L } & \text { Secondary lateral visual cortex } \\ \text { V2M } & \text { Secondary medial visual cortex } \\ \text { V2MM } & \text { Secondary medio-medial visual cortex } \\ \text { V2ML } & \text { Secondary medio-lateral visual cortex } \\ \text { VEP } & \text { Visual evoked potential }\end{array}$




\section{Introduction}

To build the perceptual scene, the mammalian brain has developed neural circuits, specialised in analysing and mixing different sources of sensory information (Teichert and Bolz 2018). This ability requires a dynamic multimodal exchange of information along all stations of the sensory pathways, from the brainstem to the cerebral cortex. After optogenetic stimulation of auditory axons in mice brain slices, recordings from visual cortex (VC) pyramidal neurons and interneurons show increased EPSC responses, demonstrating the combined effect of excitation and inhibition underlying intermodal horizontal interactions (Ibrahim et al. 2016).

When one sensory system fails, the brain cortex reorganises its neural network to preserve intermodal processing, which is known as cross-modal plastic reaction. In deafened ferrets, de novo emergent somatosensory responses have been shown by single units recorded in the auditory cortex (AC), undoubtedly demonstrating a multimodal sensory conversion in the brain cortex after sensory deprivation (Allman et al. 2009). Since receptive fields result from inhibitory GABA interactions, demonstrated by iontophoresis (Firzlaff and Schuller 2001; Tremere et al. 2001), sensory conversion may reflect imbalanced multimodal neurotransmission between cortices.

In deaf mice, a potential increase in $\mathrm{VC}$ activation has been demonstrated by c-Fos overexpression (Teichert and Bolz 2017). In addition, after bilateral long-term deafness, c-Fos and Arc/Arg3.1 expression is significantly increased in immunoreactive neurons in the VC (Pernia et al., 2017). Thus, these data indicate that hearing deprivation induces long-term bimodal adaptive reorganisation of cortical neuronal networks and altered functional interactions between the VC and AC. Visual evoked potentials recordings (VEPs) is a fairly simple technique which provides reliable information on visual cortex activation, which has long been used in diagnostics (Hudnell et al. 1990). In humans, VC over-activation after permanent and longterm deafness has been demonstrated by VEPs (Neville et al. 1983; Campbell and Sharma 2014).

Cross-modal cortical interactions after deafness have been analysed from different points of view in animal models (Finney et al. 2001; Bizley et al. 2007; Allman et al. 2009; Meredith and Lomber 2011; Kok et al. 2014; among others); however, little evidence is available on how sensory cortices react after long-term deafness in adults. Thus, this study aimed to explore very long-term VC over-activation by long latency cortical VEP recordings under flash-light stimulation in a rat model of bilateral auditory deprivation; the model was also used to evaluate neuronal activation by analysing the gene expression of the activity-dependent early gene c-Fos.

In the brain cortex, activity-dependent synaptic plasticity is triggered after changes in synaptic strength of cortical neuronal networks induced by homeostatic regulation (Turrigiano et al. 1998-for review see Pérez-Otaño and Ehlers 2005). Consequently, imbalances between cortical excitation and inhibition, as expected after permanent auditory deprivation, may induce changes in neurotransmission and neuronal regulation in the sensory cortex. Therefore, this study also aimed to perform analysis of a well-characterised homeostatic plasticity regulator (Arc/Arg3.1), and neurotransmission markers for excitation (GluA2/3 AMPA R subunits) and inhibition (Gad65 and 67, GABA receptor subunits and parvalbumin) in the AC and VC.

\section{Materials and methods}

This study was conducted according to Spanish (Royal Decree 53/2013-Law 32/2007) and European Union (Directive 2010/63/EU) guidelines for the care and use of laboratory animals. Protocols were approved by the Ethics Committee on Animal Experimentation of the University of Salamanca (Permit Number: 2012-265). Surgery was performed under monitored anaesthesia and all precautions were taken to minimise suffering. In this study, a total of 37, 3-month-old, Wistar rats weighing 250-300 g were used.

\section{Experimental groups}

Group 1: VEP recordings. Control group $n=3$; bilateral deaf animals $n=6$.

Group 2: RT-qPCR to analyse the gene expression of GluA2 AMPA R subunit, Gad65, Gad67, Parvalbumin, Gabral and Gabbr2, and early genes c-Fos and Arc/Arg3.1. Control group $n=6$; bilateral deaf animals $n=6$.

Group 3: GluA2/3 AMPA R subunits immunocytochemistry. Control group $n=4$; bilateral deaf animals $n=4$.

Group 4: GAD67 and $P V$ immunocytochemistry. Control group $n=3$; bilateral deaf animals $n=5$.

\section{Surgery}

Surgery and hearing loss validation in this animal model of long-term hearing deprivation have been extensively detailed in a previous paper published by our laboratory (Pernia et al. 2017). Deep anaesthesia was induced by intramuscular injections of ketamine chlorhydrate $(30 \mathrm{mg} / \mathrm{kg} \mathrm{BW}$; Imalgene 1000, Rhone Méreuse, Lyon, France) and $5 \mathrm{mg} /$ 
$\mathrm{kg}$ xylazine chlorhydrate $(5 \mathrm{mg} / \mathrm{kg}$ BW; Rompun, Bayer, Leverkusen, Germany). Animals were placed on a heating pad to maintaining the temperature at $37^{\circ} \mathrm{C}$, protecting the eyes by applying a drop of ophthalmic gel (Methocel ${ }^{\circledR} 2 \%$, Omnivision GmbH, Puchheim, Germany). Using a surgical microscope (Wild M650, Wild Heerbrugg, Switzerland), bilateral lesions were performed by puncturing the cochlea through the ears with a sterile straight needle (gauge $20 \mathrm{~g}$ ) after middle ear ossicular chain removal. The animals were kept on the heating pad maintaining the temperature at 37 ${ }^{\circ} \mathrm{C}$ (Thermostatic blanket low noise, model RTC-1, Cibertec, Madrid, Spain) after surgery until they woke up. Buprenorphine was subcutaneously injected in the back of the rats (0.05 mg/kg; Buprex ${ }^{\circledR} 0.3 \mathrm{mg}$ RB Pharmaceuticals Limited, Slough Berkshire, UK) for analgesia $1 \mathrm{~h}$ after the surgery and then every $8 \mathrm{~h}$ for the following $72 \mathrm{~h}$.

\section{Deafness assessment: auditory brainstem recordings}

Auditory brainstem recordings (ABRs) were performed in deaf and control animals to show the effectiveness of cochlear puncture in inducing profound hearing loss.

In all four experimental groups, bilateral ABRs were performed before surgery, after surgery, and immediately before euthanasia. Recordings were performed under anaesthesia (ketamine-xylazine) using a close-field real-time signal processing (Tucker-Davis Technologies [TDT], System RZ-6, Alachua, Fl, USA) for groups 2, 3 and 4. In group 1, the anaesthesia protocol for ABRs was similar to that used for VEPs recordings (see below).

Three subcutaneous needle electrodes were used for the recordings, placed at the vertex (active electrode), with the mastoid ipsilateral to the stimulated ear (reference) and the mastoid contralateral to the stimulated ear (ground electrode). Sound stimuli of a 5-ms (ms) window with $0.1 \mathrm{~ms}$ alternating polarity click with a repetition rate of 11 bursts/s were delivered in 10-dB ascending steps from 10 to $90 \mathrm{~dB}$ SPL. The stimuli were performed in close field using a magnetic speaker [TDT-MF1 Multi-Field Magnetic Speaker, Tucker-Davis Technologies (TDT), Alachua, FL, USA] connected through a 10-centimetre-long plastic tube $\left(\right.$ Tygon $^{\circledR}$ formula 2375, Sant-Gobain Performance Plastics, Akron, $\mathrm{OH}, \mathrm{USA}$ ), inserted into the external auditory canal. This approach resulted in a 1.4-milisecond delay for stimulus arrival at the tympanic membrane. Responses were averaged 1000 times. Evoked potentials were amplified and digitised using a Medusa RA16PA preamplifier and RA4LI head stage [Tucker-Davis Technologies (TDT), Alachua, FL, USA]. The final signal was filtered with a 500-Hz high-pass filter and a 3000-Hz low-pass filter.

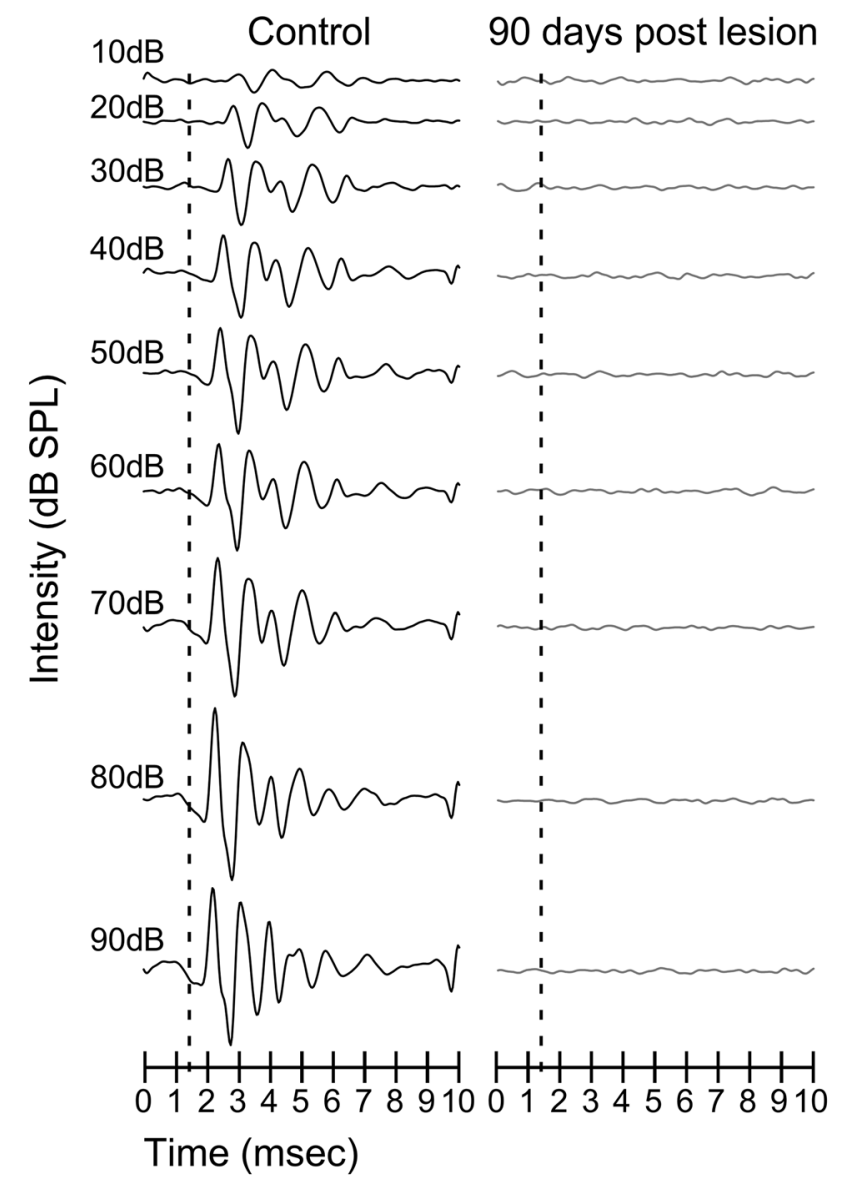

Fig. 1 Example of auditory brainstem recordings made before (left) and 90 days after cochlear puncture (90 days post-lesion-right). No waves were detected after click stimulus presentations from 10 to $90 \mathrm{~dB}$, which ensures long-term deafness of the animals in our model of bilateral hearing deprivation

No sound evoked auditory brainstem activity was shown in any of the four deaf animal groups (for an example, please see Fig. 1).

\section{Visual evoked potentials}

Animals from group 1 were placed in a cage to induce gas anaesthesia by applying 5\% sevoflurane. Once the hind paw and corneal reflexes disappeared, the animals were placed in a stereotaxic frame to implant stainless screws $(1.2-\mathrm{mm}$ diameter, 4-mm length, Stoelting Co., Wood Dale, IL, USA). A small guide hole was created using a hand drill; screwing was then started by lowering the screws through the bone without touching the cortex and permanently attaching them with dental acrylic cement (DuraLay, Reliance, Dental Mfg. Co., Worth, IL, USA). Pedestal provided an excellent and stable signal-to-noise ratio and avoided potential movement during the experiments (Makowiecki et al. 2015). 

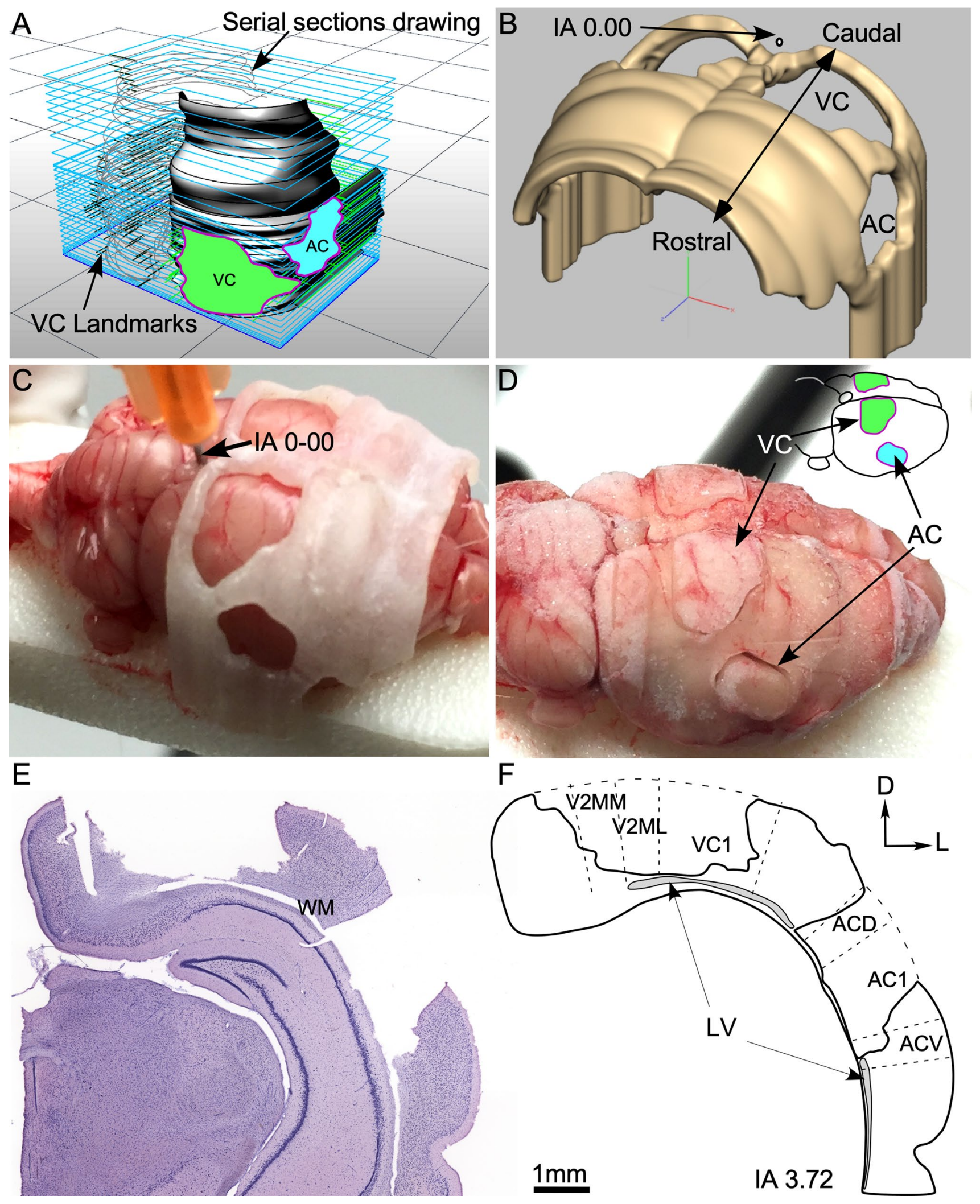
4 Fig. 2 Method for printing a 3D mold of the rat brain, designed for precise and controlled tissue extraction of separate samples from the auditory (AC) and visual (VC) cortices. a Digitised stacked drawings from coronal serial sections obtained from Paxinos atlas. Please note the holes defined for delimiting AC (in blue) and VC (in green) in the stack reconstruction. b Resulting solid model after 3D printing of the mask. Surface holes precisely delimit AC and VC. c Tissue extraction procedure. Printed mask was placed carefully on the brain surface. For defining the correct position of the matrix in relation to stereotaxic coordinates, a guide needle was inserted in interaural (IA) 0.00 in the brain (arrow). $\mathbf{d}$ Mask and brain together were immersed in liquid nitrogen. After careful demarcation with a small scalpel, AC and VC (arrows) were delineated on the surface of the brain before tissue extraction. e Method for checking the accuracy of tissue extraction. Example of a coronal Nissl-stained section after AC and VC extraction guided by the 3D mask. f Superimposition to the section silhouette of cytoarchitectural landmarks taken from an equivalent IA section of Paxinos atlas. This approach makes it possible to confirm the precision and accuracy of the extraction of the two sensory cortices in separate samples for RT-qPCR analysis. $A C 1$ primary auditory cortex, $A C D$ dorsal auditory cortex, $A C V$ ventral auditory cortex, $V C 1$ primary visual cortex, $V 2 M M$ secondary medio medial visual cortex, $V 2 M L$ secondary mediolateral visual cortex, $L V$ lateral ventricle, $W M$ white matter

The active electrode was placed on the monocular VC coordinates (AP: - 7.5; ML 3.5), and the reference electrode was placed in the contralateral hemisphere (AP: -5.5 ; ML 3.5).

EEG recordings started a week after screw implantation and 90 days after cochlear puncture. EEG recording in the control group were made after the same time lapse as that of the bilateral deaf group. Animals were anaesthetised (1.5-2\% of sevoflurane) to maintain stable slow-wave activity. The body temperature was maintained at $37{ }^{\circ} \mathrm{C}$ using a homeothermic blanket system with a rectal thermometer probe (Harvard Apparatus, Holliston, MA, USA). For VEP recordings, the animals were placed in a dark cage and allowed to adapt to the darkness for $5 \mathrm{~min}$. Visual stimulation consisted of flashes at $0.5 \mathrm{~Hz}$. VEPs were obtained after averaging 150 stimuli. A differential amplifier (Model 1700 A-M System, LLC, Carlsborg, WA, USA) was used to continuously record the EEG signal. The signal was amplified $(\times 1000)$, filtered $(1-500 \mathrm{~Hz})$, digitized at $20 \mathrm{kHz}$ by a 1401 CED A/D convertor card (Cambridge Electronic Design, UK) and stored using Spike 2 software (Cambridge Electronic Design, UK) in a PC for online checking and subsequent analysis. N1 wave latency was defined as the time in seconds (s) from the stimulus onset to the positive peak of the wave. The amplitude of wave N1 was measured as the peak-to-peak amplitude between the preceding negative to the subsequent N1-positive peak.

\section{Tissue extraction for RT-qPCR gene expression analysis}

Animals from group 2 were anaesthetised and decapitated and, after quick brain extraction (less than $4 \mathrm{~min}$ ), the AC and $\mathrm{VC}$ were delimited by superimposing a 3D printed mask. The mask was designed using digitalised drawing lines of coronal serial sections from the Paxinos and Watson atlas (from IA 0.12 to 12.24) (Fig. 2a, b). A plastic brain matrix was digitally built after delimiting AC and VC landmarks in stereotaxic atlas digital pictures (Design $\mathrm{X}^{\circledR}$ program) and printed with a 3D System 3510SD (Visijet M3 Crystal). The 3D plastic matrix was positioned carefully on the brain surface using a guide needle inserted in the brain in IA 0.00 (Fig. 2c). After being quickly frozen in liquid nitrogen, both brain and plastic matrix, AC and VC from both hemispheres were precisely extracted using a small $(0.7 \mathrm{~mm})$ ad hoc trowel (Fig. 2d). Subsequently, AC and VC tissues were stored at $-80^{\circ} \mathrm{C}$ until use.

To ensure the accuracy of AC and VC tissue extraction, coronal serial sections of brains after tissue extraction were stained with $1 \%$ cresyl violet for 10 min (C-violet 1791; Sigma-Aldrich Co., St. Louis, MO, USA). Staining differentiation was in $96 \%$ alcohol + acetic acid and sections were finally dehydrated in increasing concentrations of alcohol from $50 \%$ to $100 \%$, followed by clearing in xylene ( $3 \mathrm{~min}$ ). Stained sections were photographed using a Leica DMRB microscope and the "Virtual slice" module of Neurolucida 8.0 (MBF-Bioscience, Williston, Vermont, USA) (Fig. 2e). Photomicrographs were superimposed with landmarks from Paxinos and Watson atlas coordinates (2005) to determine dorso-ventral and rostro-caudal limits of the extracted AC and VC (Fig. 2f). All areas of extraction (holes with loss of tissue in the Nissl stained sections) were shown inside the coordinates of visual and auditory cytoarchitectural limits (Fig. 2e, f).

\section{RNA isolation}

Total RNA was purified from the collected and homogenised cortices to study the gene expression of target mRNAs using RNAqueous-micro kit ${ }^{\circledR}$ (Invitrogen, Thermofisher, Carlsbad, CA, USA), performed according to the manufacturer's instructions. RNA concentrations and quality were assessed using an RNA 6000 Nano LabChip kit (Agilent Technologies, Palo Alto, CA, USA) and an Agilent 2100 Bioanalyzer to assess the integrity of the $18 \mathrm{~S}$ and $28 \mathrm{~S}$ rRNA bands, as well as an RNA integrity number (RIN), with 0 corresponding to fully degraded RNA and 10 corresponding to intact RNA. For all RT-qPCR analyses, only RNA samples with a RIN of at least 7.5 were used; most samples had a RIN of at least 8.0, thus fulfilling one of the requirements of an optimal RT-qPCR experiment according to Fleige et al. (2006). 


\section{Quantitative reverse-transcription real-time PCR (RT-qPCR)}

Total RNA $(1 \mu \mathrm{g})$ primed with oligo-dT and random hexamer primers was reverse-transcribed into cDNA at $37{ }^{\circ} \mathrm{C}$ for $2 \mathrm{~h}$ using the first-strand cDNA synthesis kit (Promega Corporation, Madison, WI, USA) in a $20 \mu \mathrm{l}$ volume and stored at $-20{ }^{\circ} \mathrm{C}$ until use, according to the manufacturer's instructions. In all cases, a reverse transcriptase negative control was used to test for genomic DNA contamination.

RT-qPCR was performed using the SYBR-Green method with a $2 \times$ master mix (Applied Biosystems, Thermofisher, Carlsbad, CA, USA). Each reaction contained $10 \mu$ of Master Mix, $0.8 \mu \mathrm{l}$ of each primer, $3 \mu \mathrm{l}$ of each cDNA sample in a different serial cDNA quantity for each gene, and Milli-Q water up to $20 \mu$. The amplification reaction was performed in the QuantStudio 7 Flex Real-Time RT-qPCR System (Applied Biosystems, Thermofisher, Carlsbad, CA, USA) with the following conditions: $10 \mathrm{~min}$ at $95^{\circ} \mathrm{C}$, followed by 40 cycles of $15 \mathrm{~s}$ at $95^{\circ} \mathrm{C}$ and $30 \mathrm{~s}$ at $60{ }^{\circ} \mathrm{C}$ depending on each pair of primers. Three RT-qPCR reactions were performed for each sample per plate, and each experiment was repeated twice. An RNA-free (negative) control sample was also used. The list of primers used is provided in Table 1. All primers had at least one primer crossing an exon-exon boundary and were designed to have similar melting temperatures and to give similar amplicon sizes.

To identify the most stable gene as an endogenous reference for RT-qPCR data normalisation, three candidates [ $\beta$-actin $(A c t b)$, glyceraldehyde 3-phosphate dehydrogenase
(Gapdh) and ribosomal protein L19 (Rpl19) (Invitrogen, Thermofisher, Carlsbad, CA, USA)] were selected, and their expression was measured by RT-qPCR. The Norm-Finder software (Andersen et al. 2004) was used to calculate intraand inter-group expression. The mean of the threshold cycle (Ct) value and the primer efficiency value of Rpl19 were used for normalisation.

The comparative $\mathrm{Ct}$ method was used to obtain quantitative data (Schmittgen and Livak 2008). After removing outliers, according to Burns et al. (2005), raw fluorescence data were used to determine the RT-qPCR amplification efficiency $(E)$ according to the equation $E=\left[10^{(-1 / \text { slope })}-1\right]$ $\times 100$. All amplifications had an $E$ value of $100 \pm 10 \%$; an $E$ value close to $100 \%$ indicates efficient amplification. The relative gene expression value (fold change, FC) of each transcript was calculated according to equation $2^{-(\Delta \mathrm{Ct} \text { "condi- }}$ tion 1" $-\Delta \mathrm{Ct}$ "condition 2"), where "condition 1" corresponds to experimental samples $(90 \mathrm{dpl})$, "condition 2 " to the samples of control animals, and the $\Delta \mathrm{Ct}$ of each "condition" is $C_{\text {t"experimental gene" }}-C_{\text {t"endogenous gene" (Livak and Schmittgen }}$ 2001; Schmittgen and Livak 2008). The standard deviation of each relative level of gene expression was calculated as a measure of data variation.

\section{Immunocytochemistry}

Animals of groups 3 and 4 were deeply anesthetised with an intraperitoneal injection of $6 \%$ sodium pentobarbitone $(60 \mathrm{mg} / \mathrm{kg} \mathrm{BW})$ and perfused transcardially with $4 \% \mathrm{p}$-formaldehyde in $0.1 \mathrm{M}$ phosphate buffer (PB).

Table 1 RT-qPCR primers used in gene expression analysis

\begin{tabular}{|c|c|c|c|c|c|c|c|}
\hline Target protein & Number GenBank $^{\mathrm{a}}$ & Primer Forward & CDNA Forward ${ }^{a}$ & Primer Reverse & CDNA Reverse ${ }^{a}$ & $\begin{array}{l}\text { Size of } \\
\text { prod- } \\
\text { ucts }\end{array}$ & $E$ \\
\hline$c$-Fos & NM_022197.2 & $\begin{array}{l}\text { ACGGAGAATCCG } \\
\text { AAGGGAAA }\end{array}$ & $569-588$ & $\begin{array}{l}\text { TGTCTCCGCTTGGAG } \\
\text { CGTAT }\end{array}$ & $640-659$ & 91 & 91.2 \\
\hline Arc/Arg3.1 & NM_019361.1 & $\begin{array}{l}\text { AGGCAGCAGCTG } \\
\text { GAGTCTTC }\end{array}$ & $2102-2121$ & $\begin{array}{l}\text { GGGTGGTACCCCTTC } \\
\text { CAGAC }\end{array}$ & $2176-2195$ & 94 & 97.77 \\
\hline GluA2 & NM_017261 & $\begin{array}{l}\text { CGGCAGCTCAGCTAA } \\
\text { AAACT }\end{array}$ & $173-192$ & $\begin{array}{l}\text { TTGTAGCTGGTGGCT } \\
\text { GTTGA }\end{array}$ & $243-262$ & 90 & 96.30 \\
\hline Gad67 & NM_017007.1 & $\begin{array}{l}\text { CGTTTGATCCGATCC } \\
\text { AGGAG }\end{array}$ & $1235-1254$ & $\begin{array}{l}\text { GAGTTTGTGGCGATG } \\
\text { CTTCC }\end{array}$ & $1331-1350$ & 116 & 98.66 \\
\hline Gad65 & NM_012563.1 & $\begin{array}{l}\text { GATCGGAACAGA } \\
\text { CAGCGTGA }\end{array}$ & $953-972$ & $\begin{array}{l}\text { GTGGCACTCACC } \\
\text { AGGAAAGG }\end{array}$ & $1059-1078$ & 126 & 95.72 \\
\hline Gabral & NM_183326.2 & $\begin{array}{l}\text { TCAGCAAAATCGACC } \\
\text { GACTG }\end{array}$ & $1468-1487$ & $\begin{array}{l}\text { GTGGGGGCTTTTAGC } \\
\text { TGAGG }\end{array}$ & $1560-1579$ & 112 & 98.47 \\
\hline$G a b r 2$ & NM_012957.2 & $\begin{array}{l}\text { GCCTCCAGCATCCAG } \\
\text { TATCG }\end{array}$ & $1192-1211$ & $\begin{array}{l}\text { GTCGGGGATGGT } \\
\text { GATTTTCA }\end{array}$ & $1307-1326$ & 135 & 91.30 \\
\hline Rpl19 & NM_031103 & $\begin{array}{l}\text { TCGCCAATGCCAACT } \\
\text { CTCGTC }\end{array}$ & $123-143$ & $\begin{array}{l}\text { AGCCCGGGAATG } \\
\text { GACAGTCAC }\end{array}$ & $191-211$ & 89 & 96.48 \\
\hline
\end{tabular}

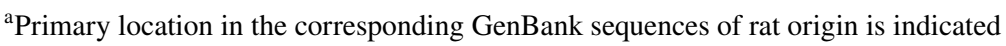

${ }^{\mathrm{b}} \mathrm{RTqPCR}$ primer efficiency $(E)$ was calculated according to the following equation: $E$ : $10^{(-1 / \text { slope })}$ 
Table 2 Summarised description of antibodies used

\begin{tabular}{llll}
\hline Antigen & Immunogen & Description & Dilution used \\
\hline GluA2/3 & $\begin{array}{c}\text { Carboxy terminus peptide of rat GluR2 conju- } \\
\text { gated to BSA with glutaraldehyde (EGYNVY- }\end{array}$ & $\begin{array}{c}\text { Polyclonal Rabbit, Merck Millipore \#AB1506; } \\
\text { RRID:AB_90710 }\end{array}$ & $1: 100$ \\
& GIESVKI) & TBS 0.05 M+ Triton-Tx 0.3\% \\
GAD67 & Recombinant GAD67 protein & $\begin{array}{l}\text { Monoclonal mouse, Merck Mil- } \\
\text { lipore \#MAB5406 clone 1G10.2 }\end{array}$ & $1: 1000$ \\
& & RRID:AB_2278725 & TBS 0.05 M+ Triton-Tx 0.3\% \\
Parvalbumin & Rat muscle parvalbumin & Polyclonal Rabbit, Swant \#PV-25; & $1: 5000$ \\
& & RRID:AB_10000344 & TBS 0.05 M+Triton-Tx 0.3\% \\
\hline
\end{tabular}

Group 3: GluA2/3 AMPA R subunits immunocytochemistry. Control group $n$ : 4; bilateral deaf animals $n: 4$

Group 4: GAD67 and PV immunocytochemistry. Control group $n$ : 3; bilateral deaf animals $n$ : 5

Brains were dissected, post-fixed and serially sectioned in the coronal plane with a sliding freezing microtome (HM 430 Sliding, MICROM International, Waldorf, Germany). Coronal serial sections ( $40 \mu \mathrm{m}$ thickness) were immunostained for GluA2/3 AMPA R subunits in group 3, and in alternate serial sections for GAD67 and PV in group 4 (for a description of the antibodies see Table 2).

Our methodological approach was designed to examine markers investigated in parallel for gene expression by RT-qPCR and for protein expression by quantitative immunocytochemistry.

In our staining procedure, paired sections from control and deaf animal groups were processed simultaneously to limit confusing differences in grey level measurements caused by immunocytochemical processing. Free-floating sections were washed in $0.1 \mathrm{M} \mathrm{PB} \mathrm{pH} \mathrm{7.6,} \mathrm{and} \mathrm{endogenous}$ peroxidase activity was subsequently inhibited by incubation in $10 \%$ methanol $+3 \% \mathrm{H}_{2} \mathrm{O}_{2}$ in $0.1 \mathrm{M}$ PB for $10 \mathrm{~min}$. Sections were washed in $\mathrm{PB}$ and $0.05 \mathrm{M}$ Tris-buffered saline, pH 8.0 + Triton X-100, 0.5\% (T9284 Sigma, St. Louis, MO, USA; TBS-Tx). Sections were then incubated in primary antisera (Table 2), for $48 \mathrm{~h}$ at $4{ }^{\circ} \mathrm{C}$. Nonspecific labelling was blocked using fetal calf serum (10\%). After washing three times in TBS-Tx, for $15 \mathrm{~min}$, all sections were incubated with an anti-rabbit biotinylated secondary antibody (biotinylated anti-rabbit IgG H1L, BA-1000; Vector, Burlingame, CA, USA) and with an anti-mouse biotinylated secondary antibody (biotinylated anti-rabbit IgG H1L, BA-2000; Vector, Burlingame, CA, USA) at 1:200 dilution in TBSTx for $120 \mathrm{~min}$ at room temperature. Sections were then washed with TBS-Tx and incubated for $180 \mathrm{~min}$ in avidin/ biotin-peroxidase (ABC complex, Vectastain Standard ABC kit PK-4000; Vector, Burlingame, CA, USA) and further washed with TBS-Tx, followed by Tris $\mathrm{HCl}, \mathrm{pH}$ 8.0. They were then incubated in 3,3-diaminobenzidine tetrahydrochloride (DAB; D-9015; Sigma-Aldrich, St. Louis, MO, USA) with $0.006 \% \mathrm{H}_{2} \mathrm{O}_{2}$ and $0.4 \%$ nickel ammonium sulphate to visualise the peroxidase reaction. One section per case was used as a negative control, by processing without the primary antibody to test the specificity of the immunostaining detection system.

\section{Quantitative immunocytochemistry}

Panoramic mosaics of the entire cortex were captured from six coronal sections for each animal at interaural coordinates (IA): $0.96,2.16,3.00,4.20,4.44$, and 4.80 corresponding with the Paxinos and Watson cytoarchitectural stereotaxic atlas. Digital photomicrographs (mosaics) were taken using a Leica DMRB microscope with a $\times 10$ objective (Leica Plan Apo). Mosaics were taken and assembled using the "Virtual slice" module of Neurolucida 8.0 (MBF-Bioscience, Williston, Vermont, USA) and adjusting the microscope illumination source before each image capture, using a stepped density filter (11 levels) $\left({ }^{\circledR}\right.$ Eo Edmund industrial optics—ref 32599, Karlsruhe, Germany).

Photomicrographs of GluA2/3 AMPA R subunits and GAD67 immunostained sections were analysed with Image J 2.0 software (USA; RRID:SCR_003070), using the default thresholding segmentation to measure optical density (OD) separately in primary and secondary ACs and VCs. After measuring the OD of the cytoarchitectural subdivisions as a whole, cortical layers were digitally cut and analysed separately.

As a reference for OD analysis, photomicrographs of CA1, CA2, CA3 and the dentate gyrus of the hippocampus were made from 3 coronal sections for each animal at 5.40 IA. The normalised hippocampal control OD for GluA2/3 and GAD67 immunoreactivity showed no significant difference between control and deaf animals (Figs. 6a, 8a).

PV immunostained sections displayed well-defined contours of neurons (good background-to-noise ratio), which enabled a clear delineation of individual neurons by density gradient segmentation. Segmentation for PV immunoreactive sections was performed using the maximum entropy threshold algorithm (Gull and Skilling 1984; Bardera et al. 2009). The number of segmented neurons was normalised to $\mathrm{N} / 10,000 \mathrm{\mu m}^{2}$. 
The mean and standard deviation of grey levels was assessed globally in all sections to cancel out differences in immunostaining intensities within and among cases. Cases with average grey levels above or below the total mean grey level \pm the standard deviation (SD) were eliminated from the analysis (only in one case from group 3).

The boundaries of AC and VC were defined according to Paxinos and Watson atlas coordinates (Paxinos and Watson 2005). We followed Palomero-Gallagher and Zilles guidelines (Paxinos 2004) to define the AC and VC layers at the rostro-caudal level. Quantitative values of each section from every case were averaged separately for each sensory cortex: primary $\mathrm{AC}(\mathrm{AC} 1)$, secondary dorsal AC (ACD), secondary ventral AC (ACV), primary VC (VC1), secondary lateral VC (V2L) and secondary medial $\mathrm{VC}$ (V2M, which contain V2MM and V2ML).

\section{Statistical analysis}

Statistical analysis was performed using the $\operatorname{IBM}^{\circledR}$ SPSS $^{\circledR}$ software, version 25.0.0.0 (IBM Corp. and SPSS Inc., Chicago, IL, USA, RRID: SCR_002865).
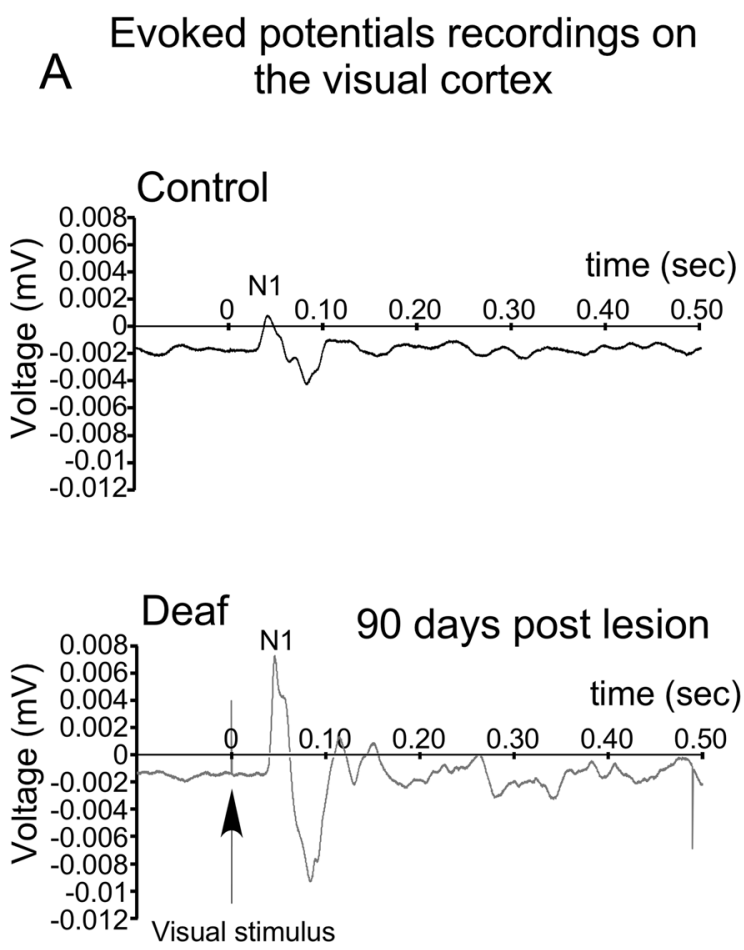

Fig. 3 a Representative VEP recording of control (top) and deaf (bottom) animals at 90 days post-lesion $(90 \mathrm{dpl})$. N1 wave amplitude (by peak to peak voltage measurements) increases three-fold after longterm deafness. b Graphic representation of the mean N1 wave amplitude, standard error and statistical analysis of N1 after hearing depri-
To identify significant differences in VEPs wave amplitude ( $\mathrm{mV}$ ) and latencies (s), a student's $t$ test was employed, which is the most common statistical test used to analyse to independent samples. The results were considered significant at $p<0.05$. The significance of the RT-qPCR analysis results was determined using a twotailed $t$ test for each gene, considering $\mid \mathrm{FCl}>1$ significant when $p<0.05$.

Differences between groups in the immunocytochemistry were assessed by general linear model univariate analysis followed by the post hoc Scheffe-test and the Bonferroni test. Differences were considered significant at $p<0.05$.

\section{Results}

\section{Electrical evoked activity}

By showing flat waves in ABRs with $90 \mathrm{~dB}$ click stimulation, we ensured sensory deprivation at 90 days after cochlear puncture (90 days post-lesion, dpl) (Fig. 1).

VEPs from $\mathrm{VC}$ after a repetitive flash stimulation protocol allowed us to distinguish primary (P1-N1) from secondary

\section{B}

\section{Statistical analysis}
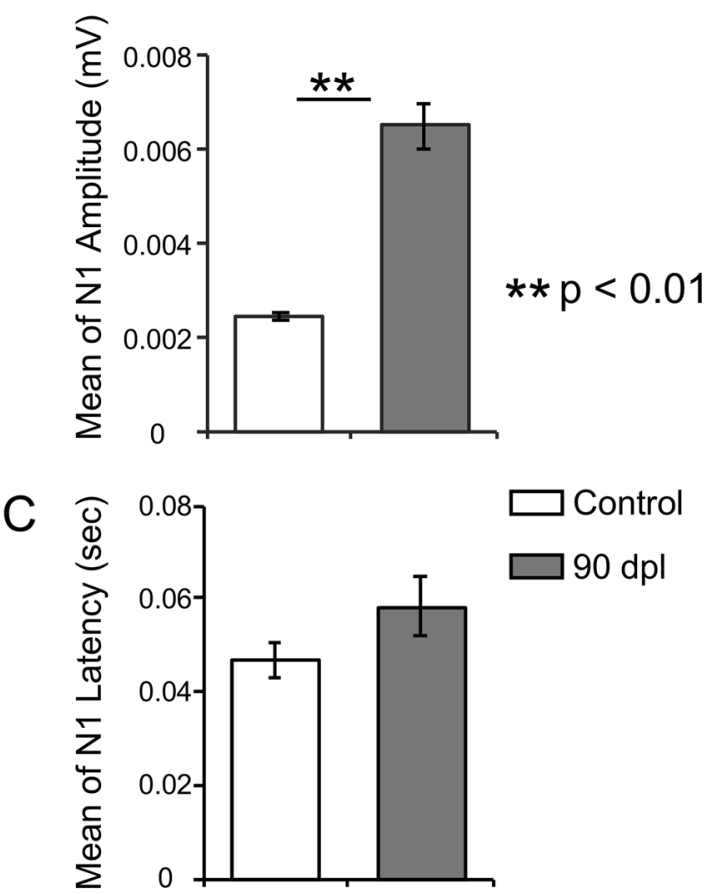

vation (control animals $n=3$; deaf animals $n=6$; ${ }^{*} p<0.01$ ). These data confirm a significant increase in N1 wave amplitude in our animal model. c Bar representation of mean N1 wave latencies, standard error and statistical analysis of $\mathrm{N} 1$ after hearing deprivation (control animals $n=3$; deaf animals $n=6$; **p $<0.01$ ) 
(P2-N2-P3) components (Fig. 3a), as described by Creel et al. (1974). Figure 3a shows representative VEPs from a control animal (top) and from a deaf animal at $90 \mathrm{dpl}$ (bottom); the increase in VEP in the deaf animal is evident by visual comparison.

For the whole population $(n=6)$, a significant increase of $156.39 \%$ was shown after comparing mean amplitudes between control and bilateral deaf animal groups (deaf animals mean $\mathrm{N} 1$ wave amplitude $\pm \mathrm{SE}=0.0062 \pm 0.0004 \mathrm{mV}$ versus $0.0024 \pm 0.000022 \mathrm{mV}$ in control ones) (Fig. 3b). No differences in $\mathrm{N} 1$ mean latency were found between groups (Fig. 3c). These results are compatible with a long-term increase in $\mathrm{VC}$ activation in deaf animals.

\section{Gene expression in the auditory and visual cortices}

Tissue samples were collected from the AC and VC using our 3D printed mask (please see "Materials and methods") (Fig. 2). After superimposing drawings from the Paxinos atlas over the Nissl staining sections, empty areas of tissue extraction were always shown inside the cytoarchitectural limits of AC and VC (Fig. 2e, f). This approach allowed us to collect tissue samples for RT-qPCR analysis of the expression levels of a selected group of genes (Arc/Arg3.1, c-Fos, GluA2, Gad65, Gad67, Gabra1, Gabbr2 and Parvalbumin) separately for the AC and the VC.

In the deaf animals of experimental group 2, the expression level showed a significant increase in $c$-Fos (fold change
Fig. 4 Bar charts illustrating changes in mRNA levels of genes in control (white columns) and deaf group (grey columns) at 90 days post-lesion $(90 \mathrm{dpl})$. Results are expressed as mean \pm standard error of fold change. Asterisks represent significant differences between groups $(* p<0.05)$. Activitydependent early genes a $c$-Fos $(p=0.021)$ and $\mathbf{b}$ Arc/Arg3.1 $(p=0.04)$. c GluA2 AMPA receptor (AMPA R) subunit $(p=0.035), \mathbf{d}$ Gad65 $(p=$ $0.03)$, e $\operatorname{Gad67}(p=0.017)$, f Gabral subunit, g Gabb-r2 subunit, h Parvalbumin

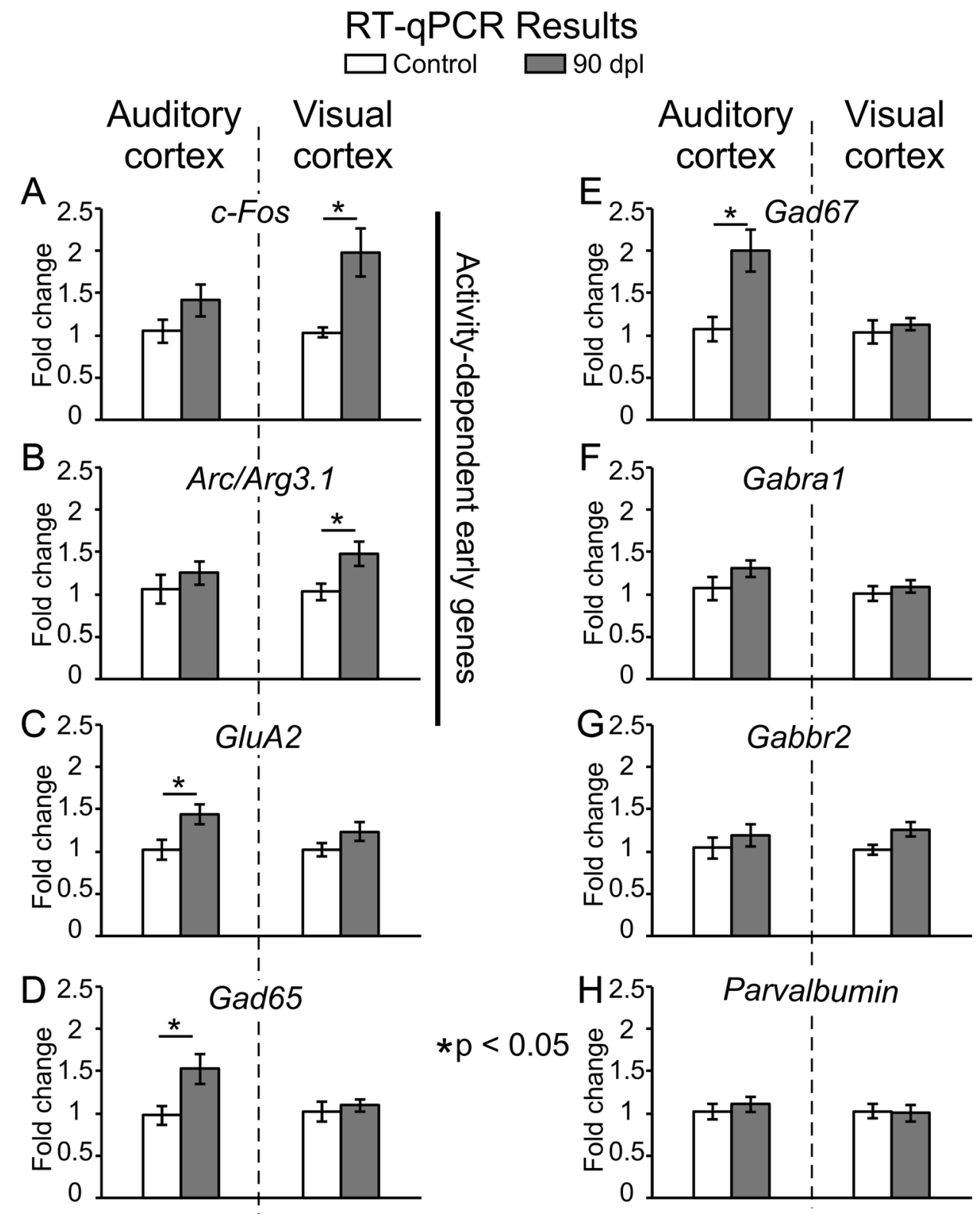


1.97; $p=0.021$ ) (Fig. 4a) and Arc/Arg3.1 (fold change 1.47; $p=0.04$ ) in the VC (Fig. 4b). The expression levels of the GluA2 AMPA R subunit showed a significant increase of 1.43 -fold $(p=0.035)$ in the AC but not in the VC (Fig. 4c).
Gad65 and Gad67 levels significantly increased 1.53- ( $p=$ $0.03)$ and 1.99 -fold $(p=0.017)$ in the AC of the deaf animals from group 2 (Figs. $4 \mathrm{~d}$ and e), respectively. However, neither the AC nor the $\mathrm{VC}$ showed significant changes

\section{Control}
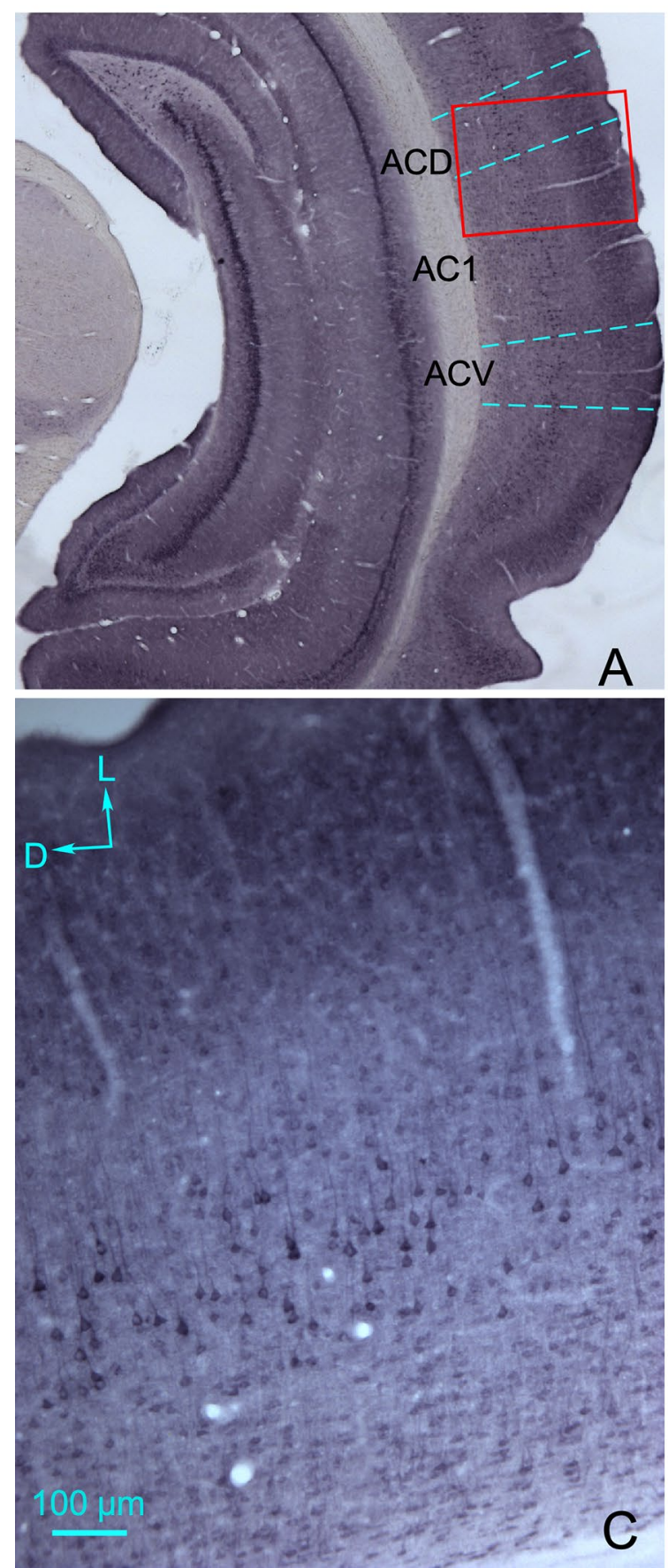

Fig. 5 Representative GluA2/3 AMPA receptor (R) subunit-immunostained coronal sections from control (a, c) and deaf (b, d) animals at 90 days post-lesion $(90 \mathrm{dpl})$ at an equivalent rostro caudal level (IA 3.60). Dotted blue lines represent cytoarchitectural subdivisions of the auditory cortex (AC). Red rectangles insets, label the AC areas

\section{Deaf}
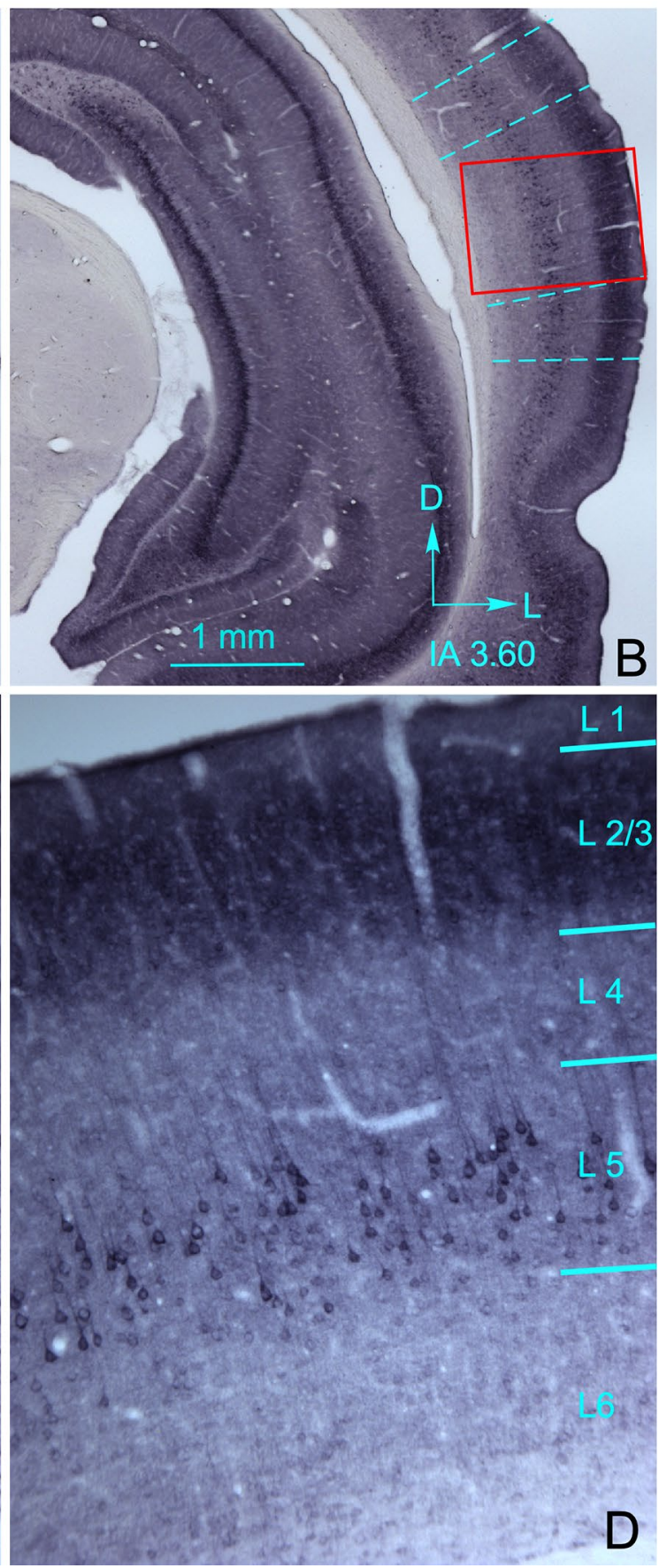

shown at a higher magnification in c, d. c, d Details of the primary auditory cortex (AC1). Notice the overall increase in immunoreactivity in layers $2 / 3$ after comparing sections of deprived animals (b, d) to those of their controls (a, c). ACD secondary dorsal AC, ACV secondary ventral AC 
after RT-qPCR analysis for Gabral, Gabbr2 or Parvalbumin when comparing controls to hearing-deprived animals (Fig. 4f-h).

\section{Protein expression in the auditory and visual cortices}

\section{GluA2/3 AMPA receptor subunits}

GluA2/3 AMPA R subunits were observed throughout the cortex with differences in immunostaining which allowed us to easily distinguish layers and cytoarchitectural subdivisions (Fig. 5a, b, dotted lines in coronal sections from control and deaf animal). Immunoreactivity was denser in the soma and dendrites of pyramidal neurons in layers $2 / 3$ when comparing the $\mathrm{AC} 1$ of deaf animals (Fig. 5d) to that of controls (Fig. 5c).

Among all cortical primary and secondary subdivisions analysed, only the OD values of AC1 and ACD were significantly increased in deaf animals (Fig. 6a). However, no significant differences were found in any of the other cortices analysed when comparing controls to deaf animals (Fig. 6a). The OD values of layers $2 / 3$ in $\mathrm{AC} 1$ and $\mathrm{ACD}$ subdivisions were significantly higher in deaf animals than in controls (Fig. 6b). No significant differences were found in the other layers. Densitometry control, by hippocampal OD analysis, showed no significant differences (Fig. 6c).

\section{Densitometry control, by hippocampal OD analysis, showed no significant difference (Fig. $6 \mathrm{c}$ )}

\section{GAD67}

Microscopically, the denser immunoreactive neuropil in layers $2 / 3$ and 5 allowed us to define cortical layers and cytoarchitectural subdivisions along the cortex (Fig. 7a, b). In particular, $\mathrm{AC} 1$ and $\mathrm{VC} 1$ were easily distinguished because their immunostaining was darker than that of surrounding secondary subdivisions (Fig. 7a, b, in both coronal sections from control and deaf animal).

In sections from deaf animals, qualitatively, $\mathrm{AC} 1$ and $\mathrm{VC} 1$ exhibited denser immunoreactive neuronal soma and neuropil, mainly in layers $2 / 3$ and 5 (compare Fig. $7 \mathrm{c}$, e with deaf animals in Fig. 7d, f).

Quantitative immunocytochemical analysis confirmed that both the primary and secondary areas of AC showed significantly higher values of normalised OD in the deaf animal group (Fig. 8a). However, in the VC, only VC1 showed a significant increase (Fig. 8a).

OD values of layers $2 / 3$ in all subdivisions of the $A C$ (AC1, ACV and ACD) and only in the VC1 were significantly higher in deaf animals (Fig. 8b). No significant differences were shown in any of the other layers. Reference densitometric analysis (hippocampus) did not show any significant differences between groups (Fig. 8c).

\section{Optical density analysis of GLUA2/3 immunoreactivity}

$$
\begin{aligned}
& \square \text { Control } \quad * p<0.05 \\
& \square 90 \text { dpl } \quad * * p<0.01
\end{aligned}
$$

\section{A}

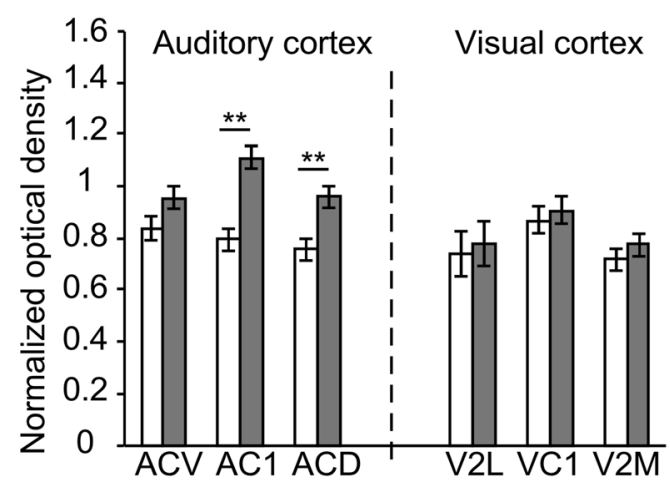

B

Layers $2 / 3$

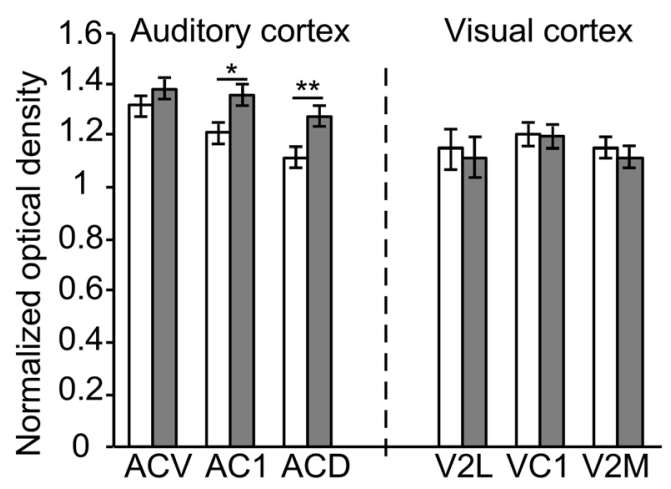

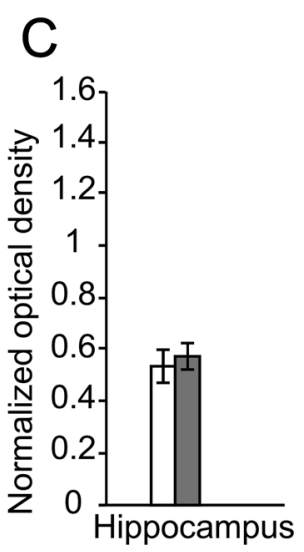

Fig. 6 a Changes in normalised optical density (OD) of GluA2/3 AMPA R subunits immunoreactivity in auditory (AC) (left) and visual (VC) (right) cortices of control (white columns) and deaf (grey columns) animals. Quantitative analyses were performed separately for primary $\mathrm{AC} 1$, secondary ventral $\mathrm{AC}(\mathrm{ACV})$, secondary dorsal $\mathrm{AC}$ (ACD), primary (VC1), secondary lateral VC (V2L) and secondary medial (V2M, which contain V2MM and V2ML) VC. Each subdivision analysed as a whole. b After separately analysing by laminae lay- ers $2 / 3$ show significant differences in AC1 and ACD. Asterisks indicate significant differences between groups $\left({ }^{*} p<0.05 ; * * p<0.01\right)$. Results are expressed as mean \pm standard error. Sections from each experimental group were incubated simultaneously with their own controls to cancel out differences in intensity measurements caused by differences in processing. $\mathbf{c}$ Bar chart illustrate non-significant differences for normalised OD values of GluA2/3 AMPA R in the hippocampus when comparing controls to deaf animals 


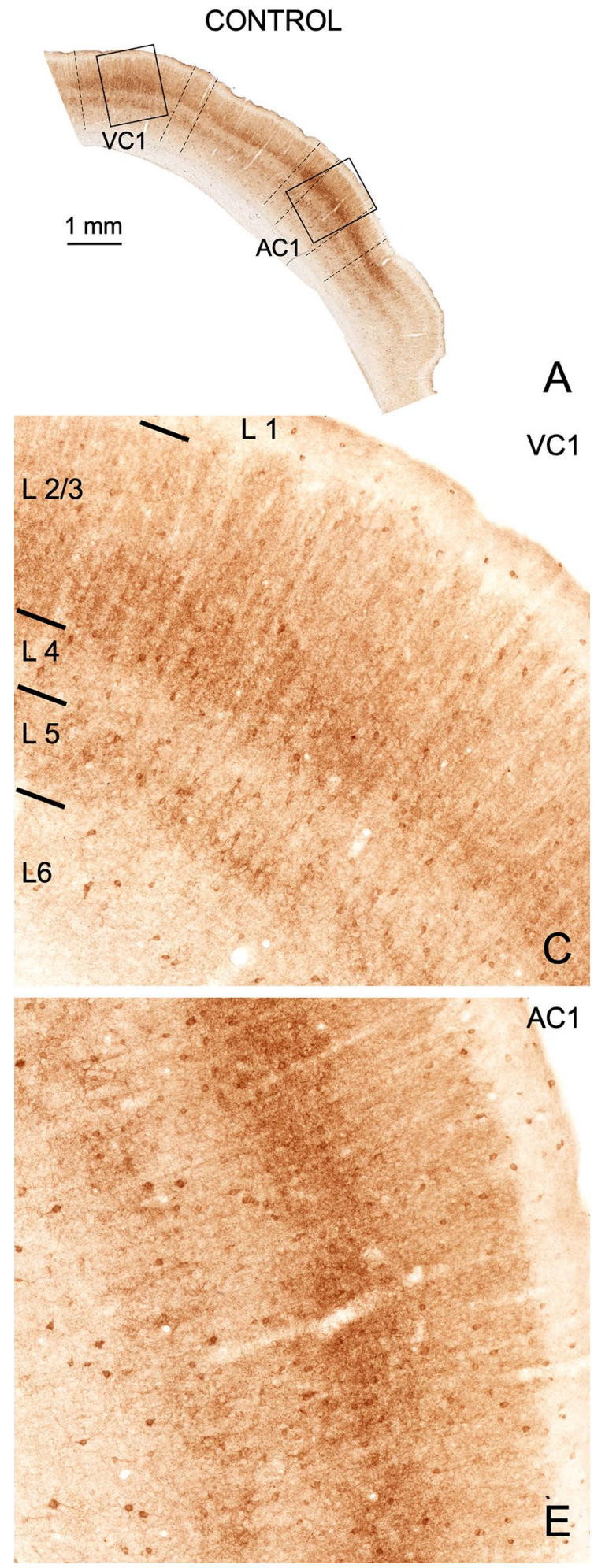

Fig. 7 Panoramic view of GAD67 immunostained coronal sections from control $(\mathbf{a}, \mathbf{c}, \mathbf{e})$ and deaf $(\mathbf{b}, \mathbf{d}, \mathbf{f})$ animals at an equivalent rostro-caudal level (IA 3.48). Denser immunoreactivity in layers $2 / 3$, facilitates the delimitation of cytoarchitectural cortical subdivisions (borders defined by dotted lines) and layers. Rectangles in $\mathbf{a}, \mathbf{b}$,
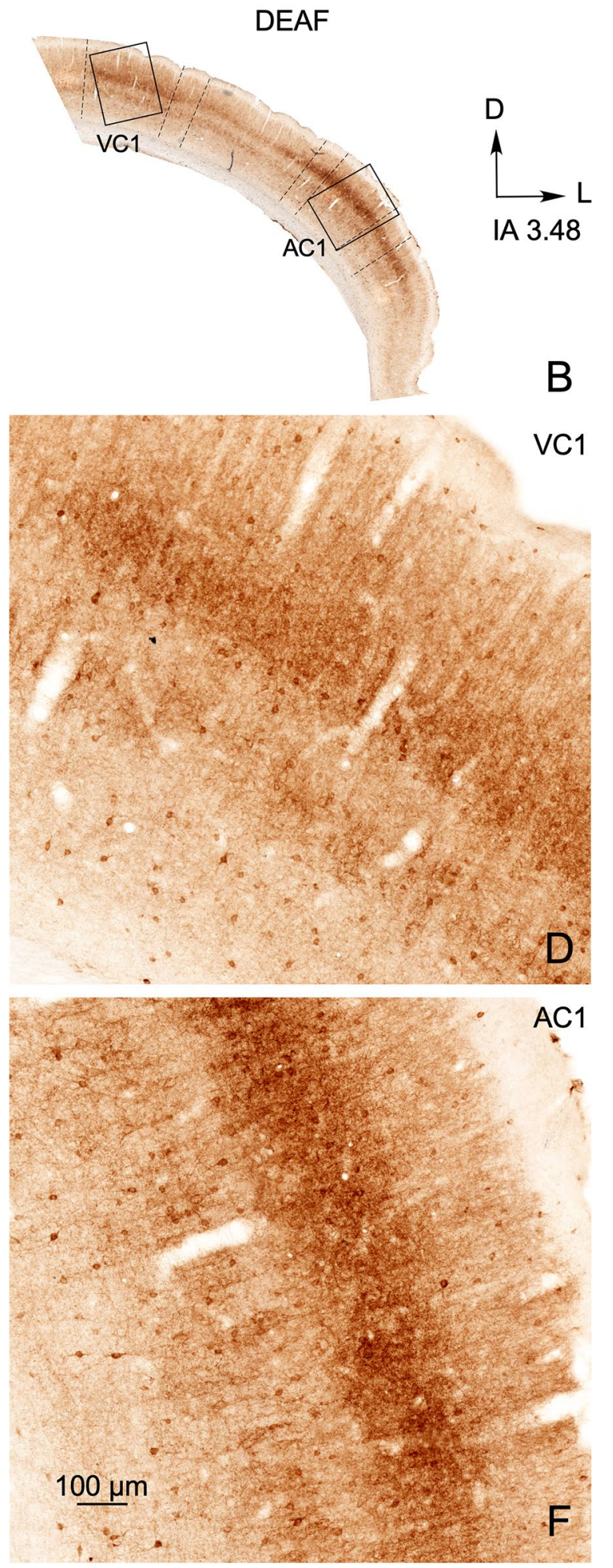

respectively, delimit details shown at a higher magnification in the bottom of the panel. Denser immunostaining in layer $2 / 3$ is noticeable when comparing the primary visual (VC1) and auditory (AC1) cortices of deaf animals $(\mathbf{d}, \mathbf{f})$ to controls $(\mathbf{c}, \mathbf{e})$ 


\section{Optical density analysis of GAD67 immunoreactivity}
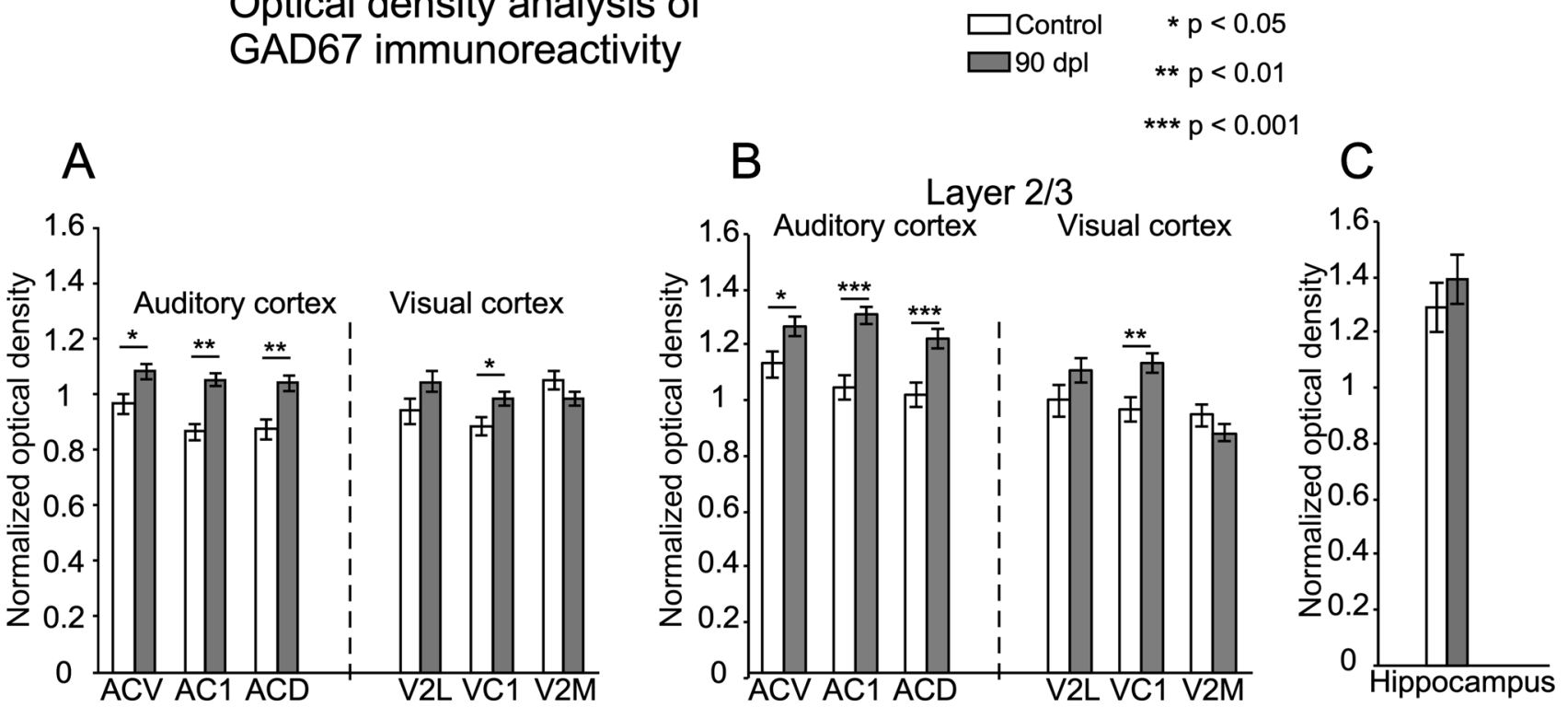

Fig. 8 a Changes in normalised optical density (OD) of GAD67 immunoreactivity in AC (left) and VC (right) of control (white columns) and deaf group at $90 \mathrm{dpl}$ (grey columns). Quantitative analyses were performed separately for AC1, secondary ventral AC (ACV), secondary dorsal $\mathrm{AC}(\mathrm{ACD})$, primary $\mathrm{VC}(\mathrm{VC} 1)$, secondary lateral VC (V2L) and secondary medial VC (V2M, which contain V2MM and V2ML). Each subdivision was analysed as a whole. b After sepa-

\section{Parvalbumin}

Microscopically, PV-immunostained sections showed labelled cell bodies and dendrites, allowing us to identify most stained neurons as medium and large interneurons along layers (Fig. 9a-d). Immunoreactive terminals are usually denser and more abundant in the neuropil of layers $2 / 3$ and 5 (Fig. 9c, d, both in control and deaf animals) and around infragranular pyramidal neurons (Fig. 9c, d, arrows). Immunoreactive somata were observed, homogenously distributed along with cortical subdivisions interspersed across all layers (Fig. 9c, d in $\mathrm{AC} 1$ details). In particular, $\mathrm{AC} 1$ and VC1 stood out from other cortical subdivisions, including secondary cortices, by their denser PV immunoreactivity (higher in the AC1). An increase in PV immunoreactivity was observed in the neuropil of $\mathrm{AC}$ in the sections from deaf animals (comparison between Fig. 9c, d). Nevertheless, these differences were not significant when morphometrically comparing OD values of the $\mathrm{AC}$ and $\mathrm{VC}$ subdivisions as a whole. However, the good signal-to-noise (backgroundto-immunostaining) ratio of PV positive neurons (Figs. 9c and $\mathrm{d}, \mathrm{AC} 1$ details) facilitated the segmentation of neurons by density gradients. After neuronal counting analysis, a significant increase in $\mathrm{PV}$ immunoreactive neurons was shown in the $\mathrm{AC} 1$ of deaf animals (90 dpl) (Fig. 10). rately analysing by laminae, layers $2 / 3$ show significant differences in all the subdivisions of $\mathrm{AC}$ and in $\mathrm{VC} 1$. Asterisks indicate significant differences between groups $(* p<0.05 ; * * p<0.01, * * * p<0.001)$. Results are expressed as mean \pm standard error. $\mathbf{c}$ Bar chart illustrate non-significant differences in normalised OD values of GAD67 in the hippocampus

\section{Discussion}

We demonstrated VC overactivation at 90 days after bilateral cochlear puncture, as shown by significant increases in N1 wave amplitudes of VEP recordings and in c-Fos gene expression (Fig. 11-1. Light red triangles). These functional and structural data suggest imbalanced intermodal processing after deafness. Such plastic reaction is likely triggered by changes in $\mathrm{AC}$ horizontal intracortical connections, as shown by significant increases in AMPA receptor and GAD immunoreactivity in layers 2/3 (Fig. 11-2, 3). In addition, a global rebound in AC inhibition was shown by increases in GAD 65 and 67 gene expression and in the number of PV-GABA interneurons (Fig. 11-3. red squares). Secondary intermodal reaction is shown in the $\mathrm{VC}$, with a significant increase in Arc/Arg3.1 and with no significant changes in AMPA R subunits (Fig. 11-4). Analysis of inhibition markers in the VC showed increased GAD immunoreactivity, specifically in the primary VC (Fig. 11-5).

\section{Auditory cortex plastic reaction}

Short-term loss of auditory inputs due to noise overexposure increases the amplitude of auditory evoked potentials in guinea pigs, which suggests functional gain enhancement of the AC after hearing deprivation (Popelár et al. 


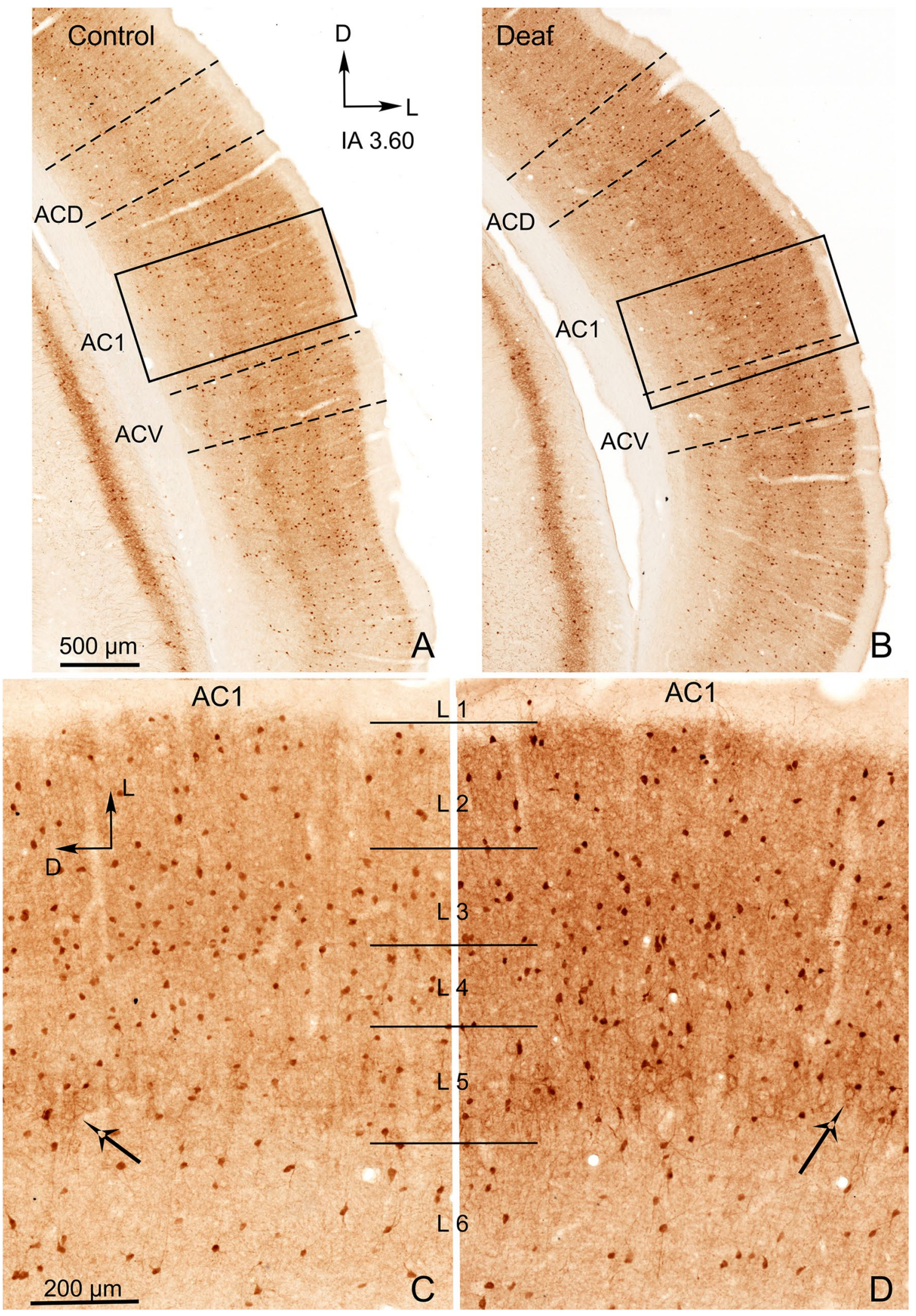

Fig. 9 Representative coronal sections immunostained for parvalbumin (PV) from control $(\mathbf{a}, \mathbf{c})$ and deaf $(\mathbf{b}, \mathbf{d})$ animals at an equivalent rostro-caudal level (IA 3.60). Dotted lines in a, b represent cytoarchitectural subdivisions of the AC. Rectangles in coronal sections in $\mathbf{a}, \mathbf{b}$ correspond to details of the primary auditory cortex (AC1) at a higher magnification in $\mathbf{c}, \mathbf{d}$. Notice the higher number of immunoreactive neurons in the microphotograph from the deaf animal in d. ACD secondary dorsal AC, ACV secondary ventral AC 


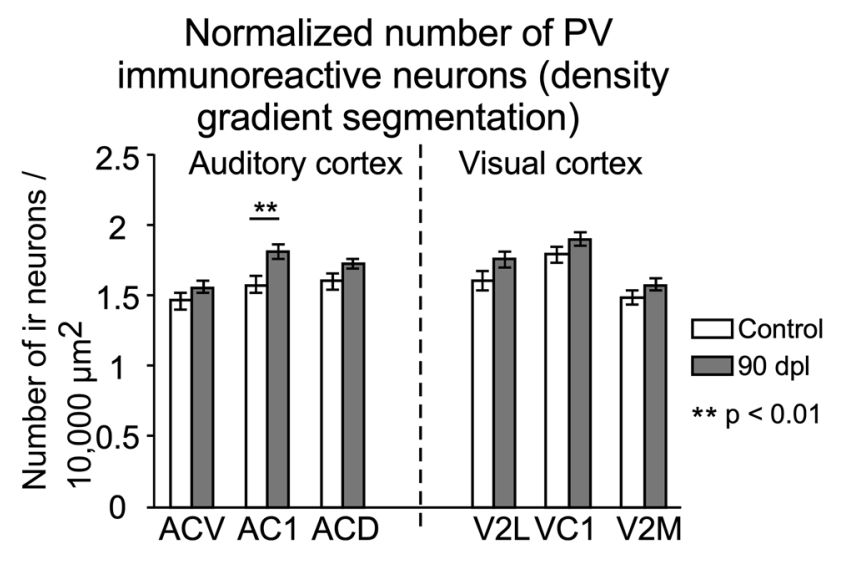

Fig. 10 Bar charts illustrate the number of PV-immunoreactive neurons segmented by density gradients in AC (left) and VC (right) of control (white columns) and deaf group at $90 \mathrm{dpl}$ (grey columns). Quantitative analyses were performed separately for AC1, secondary ventral AC (ACV), secondary dorsal AC (ACD), primary VC (VC1), secondary lateral VC (V2L) and secondary medial VC (V2M, which contain V2MM and V2ML). Asterisks indicate significant differences between groups $(* * p<0.01)$. Results are expressed mean \pm standard error

1987). Similar increases have also been observed in chinchillas after damaging inner hair cells by ototoxicity (Qiu et al. 2000). Hearing loss in cochlear ablated gerbils also raises excitability in layers $2 / 3$ of $\mathrm{AC}$, thus demonstrating increased EPSC amplitude by whole-cell recordings in brain slices (Kotak et al. 2005). Moreover, after visual deprivation in mice, GluA2 and GluA3 gene expression is also up-regulated in the VC (Tropea et al. 2006). Changes in GluA1-GluA2 protein expression, along with increases in the amplitude of spontaneous EPSCs in VC layers 2/3 pyramidal cells, have also been shown after visual deprivation in rats, which indicates increased cortical excitability induced by horizontal intermodal connections (Goel et al. 2006). In the AC of our deaf animals, the cellular stock of GluA2/3 AMPA R subunits is increased in pyramidal neurons of layers $2 / 3$, as shown by the significant higher OD values of immunoreactive products and by microscopic inspection of sections (Figs. 6a, c, 11-2). This increase in GluA2/3 immunoreactivity in AC layers $2 / 3$ could be a homeostatic response resulting after the loss of thalamic drivers induced by deafness in combination with an imbalanced intermodal interaction from the over-activated VC.

In this study, we collected well restricted samples from the $\mathrm{VC}$ and $\mathrm{AC}$ using a 3D printed mask superimposed on the brain surface. After applying this method, and testing the extraction in serially Nissl sections, we were able to analyse separately both cortices. Consequently, the results of significant fold changes in GAD reflect an extensive increase in GABA gene expression and potentially in GABA synthesis, because all neurons from primary and secondary cortices are present in our samples. Gad65 and Gad67 gene expression up-regulation exclusively in the AC (Fig. 4d, e) and increased immunoreactivity of GAD 67 and PV (GABA) interneurons (Fig. 11-3) indicate a rebound in inhibition in the AC. Layers 2/3, specifically denser in GAD67 immunocytochemistry, are the main recipient for horizontal crossmodal circuits in the brain cortex (Paperna and Malach 1991; Ibrahim et al. 2016). These horizontal connections can regulate cross-modal activation, as shown by elicited EPSCs in pyramidal and PV interneurons in VC layers 2/3 after light spot stimulation of AC axons (Ibrahim et al. 2016). In our material, the AC layer 2/3 of deaf animals are significantly more densely immunostained for GluA2/3 and for GAD67 (Fig. 11-2, 3). These findings highlighted the key role of horizontal feedbacks in over-activating the VC and maintaining the global inhibitory response of the AC. However, no significant changes in GABA receptor (Gabral and Gabbr2) gene expression were detected by RT-qPCR.

GABAA ionotropic receptors have rapid rates of constitutive endocytosis (Kittler and Moss 2003; Kittler et al. 2005). In addition, GABAB metabotropic receptors present fast constitutive internalisation (Maier et al. 2010; Hannan et al. 2011), whose rate appears to depend on the GABABR2 subunit (Duthey et al. 2002; Margeta-Mitrovic et al. 2001; Hannan et al. 2011). After depolarising conditions by electric stimulation in cultured neurons, GABAA receptor subunit membrane expression increases without changes in the total quantity of protein, suggesting an increase in subunit trafficking without changes in transcription or synthesis (Rannals and Kapur 2011). Additionally, the activation of AMPA glutamate receptors in cortical cell cultures down-regulates GABAB receptors, as shown by western blot (Maier et al. 2010). Thus, based on the rates of internalisation and recycling of these receptors, increased inhibition (as shown by GAD analysis) may occur, with no relevant changes in the gene expression of GABA receptor subunits (as shown by RT-qPCR).

Immunocytochemistry for calcium-binding proteins (Celio 1986, 1990) and neuropeptides (Hendry et al. 1984) (PV, Calbindin/somatostatin and calretinin/vasointestinal peptide) identified three main phenotypes for GABA interneurons in the cortex (Kawaguchi and Kubota 1997). Furthermore, quantitative immunohistochemistry in the rat brain cortex has shown that approximately $40 \%$ of interneurons are immunoreactive to PV (Celio 1986; Lee et al. 2010; please see a review in Rudy et al. 2011). PV reactive interneurons correlate with the classical neuronal types of Basket and Chandelier cells (Kawaguchi and Kubota 1997). Thus, in our PV quantitative immunocytochemical analysis, we have explored approximately $40 \%$ of GABA interneurons of $\mathrm{VC}$ and $\mathrm{AC}$ and the two major short axon neuronal types involved in inhibitory regulation of cortical columns (Basket and Chandellier neurons-Fig. 11-3). After demonstrating, 
Fig. 11 Working hypothesis about cross-modal reaction between auditory and visual cortex after long-term hearing loss. After deafness, altered auditory thalamic inputs induce VC overactivation (1) and increased AMPA R subunit immunoreactivity in layers $2 / 3$ (2). The increase in the number of PV-GABA interneurons in AC suggests increased inhibition of cortical column microcircuits (3). VC over-activation (1) induces a homeostatic compensatory reaction, as shown by increases in Arc/Arg3.1 gene expression (4). In our model, two mechanisms of compensation (labelled in the diagram as circles with arrows $\mathrm{A}$ and $\mathrm{B}$ ) dynamically work in combination: a imbalanced reciprocal horizontal connections and $\mathbf{b}$ increased Arc/Arg3.1 expression in VC, which tend to rebalance $\mathrm{VC}$ by internalization of membrane glutamate receptors in pyramidal neurons. Triangles indicate pyramidal neurons and small squares indicate interneurons. Red: more activation and Green: less activation

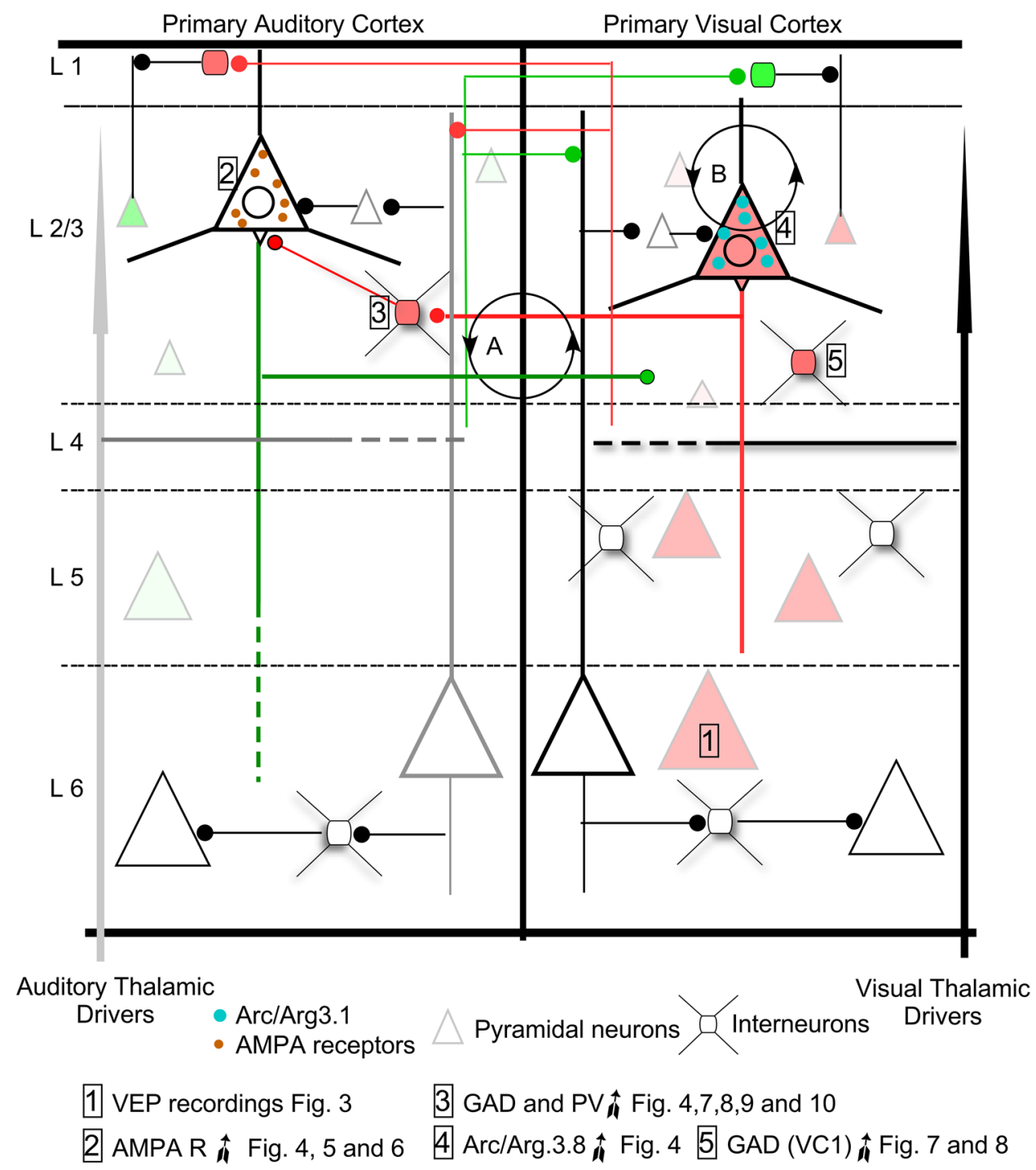

by depolarising current pulse and whole-cell recordings in rat brain slices, that PV cells have short-duration action potentials and fire repetitively without frequency adaptation, they were termed fast-spiking (FS) neurons (Kawaguchi 1993; Kawaguchi and Kubota 1993). Fast-spiking parvalbumin positive (FS-PV) interneurons closely regulate the discharge rate of pyramidal neurons, as clearly demonstrated by electrophysiology, more specifically by paired patch clamp recordings in brain slices of the cat VC (Tamás et al. 1997). A similarly tight regulation has been shown after in vivo patch-clamp recordings following optogenetic stimulation of Arch virus (Atallah et al. 2012). The FS of these interneurons is attributed to the high calcium affinity of the PV, which responds to increases in neuronal firing rate by buffering intracellular free $\mathrm{Ca}^{2+}$ concentrations (Chard et al. 1993). Consequently, significant increases in the number of FS-PV interneurons, which we have shown in the $\mathrm{AC}$, would indicate that neuronal soma and dendrites are best detected by their higher immunoreactivity as a result of increased activation. Such an assertion is also indirectly supported by experiments made in rat hippocampal slices, which have shown that reduced $\mathrm{Ca}^{2+}$ inflow in FS-PV neurons by calcium chelators decreases the IPSC amplitude of pyramidal neurons (Bucurenciu et al. 2008). Considering the common phenotype of FS-PV and GABA neurons (Kawaguchi and Kubota 1997) and the known functional role of these interneurons, the increase in the immunoreactivity of FS-PV interneurons that we demonstrated could be related to an increase in GABA neurotransmission, thus further supporting, along with the GAD results, an increase in $\mathrm{AC}$ inhibition.

\section{Visual cortex plastic reaction}

In congenital deafness (Neville et al. 1983) and after acquired hearing loss (Campbell and Sharma 2014), VEPs 
recordings have shown increases in N1 wave amplitudes, suggesting $\mathrm{VC}$ over-activation after long-term deafness in humans. In our experimental animal model, the mean of peak to peak N1 wave amplitude was $156.39 \%$ higher in deaf animals than in controls. N1 wave amplitude after VEP recordings reflects higher global electrical responses and VC over-activation after visual stimulation (Fig. 11, 1).

c-Fos is a marker of neuronal activity which is rapidly induced after neuronal depolarisation (Greenberg et al. 1986; Morgan and Curran 1988; Bartel et al. 1989; Joo et al. 2016). Accordingly, increased VC activation is confirmed by the overexpression of the activity-dependent early gene c-Fos (present results) and by significant increases in immunoreactive neurons in the VC (Pernia et al. 2017). Furthermore, a link between Arc/Arg3.1 expression and neuronal electrical activity has been demonstrated by the increase in Arc/Arg3.1 gene expression after high-frequency stimulation of the hippocampus (Lyford et al. 1995; Steward et al. 1998, 2015). Thus, indirect evidence at a cellular level of VC overactivation in our animal model also arises from significant increases in the expression of activity-dependent early genes c-Fos and Arc/Arg3.1.

The homeostatic plasticity of brain neuronal network regulation implies that any change in its activation may induce changes in receptor synthesis, trafficking and internalisation, which work in combination to adjust synaptic strength and/or neuronal membrane excitability (Turrigiano et al. 1998-for review see Pérez-Otaño and Ehlers 2005). The role of Arc/Arg3.1 in balancing excitability of neuronal networks by AMPA R regulation was analysed in mice hippocampal slices. The results showed that, after electric stimulation, Arc/Arg3.1 mediates the removal of GluA2/3 AMPA R subunits from the neuronal membrane and reduces the amplitude of EPSCs (Rial Verde et al. 2006). In our results, increases in activation and Arc/Arg3.1 expression in the VC did not coincide with any changes in GluA2 and GluA3 AMPA receptor subunits. Accordingly, considering the role of Arc/Arg3.1 in synaptic plasticity regulation, its increased expression suggests dynamic homeostatic compensation for $\mathrm{VC}$ neuronal network stabilisation after overactivation (Fig. 11b) (Rial Verde et al. 2006; Bramham et al. 2008; Wall and Corrêa 2018). Our results from all neuronal markers analysed in the VC indicated an increase in GAD67 immunostaining restricted to $\mathrm{VC} 1$, with no overall changes in gene expression in the $\mathrm{VC}$. Because $\mathrm{VC} 1$ is the main recipient for visual primary thalamic inputs (Kharazia and Weinberg 1994), increased GAD67 immunostaining could be interpreted as a reactive response to changes in thalamocortical activation after deafness. Indeed, increased EPSC amplitude in VC1 layer 4 has been shown by recordings in deaf mice brain slices, in accordance with a potential overactivation of visual thalamic primary afferents after deafness (Petrus et al. 2014). However, our data thus also suggests that changes in GAD expression in the $\mathrm{VC} 1$ may result from imbalanced horizontal intermodal feedback between $\mathrm{AC}$ and VC (see below) (Fig. 11a).

\section{Concluding remarks and working hypothesis}

Cross-modal balance for sensory processing between primary cortices results from a combination of thalamic driver activation, horizontal intermodal connections and intrinsic microcircuit elaboration of neuronal responses in the cortical columns.

VC overactivation (demonstrated by c-Fos analysis and VEPs recordings) could be generated by imbalanced horizontal interactions, as shown by changes in immunoreactivity specifically in layers $2 / 3$. However, such imbalances do not equally affect both primary cortices, because GABA interneurons specifically increase in $\mathrm{AC} 1$ and GAD increases in primary and secondary ACs and in primary VC. Increases in gene expression and protein expression of AMPA receptors in layer $2 / 3$ of the AC suggest an effort to compensate for changes in the activation of thalamic drivers. Overall, these results suggest that increased AC inhibition (GAD and PV-GABA neurons) is induced primarily by its plastic reorganisation after deafness and secondarily by the horizontal interaction from the over-activated VC (Fig. 11). Under these conditions, two homeostatic mechanisms actively work for dynamic compensation of the imbalanced bimodal relationship between AC and VC after deafness: (1) imbalanced horizontal cortical feedback (Fig. 11-a), and (2) Up-regulated Arc/Arg3.1 expression (which supports the hypothesis that a reactive homeostatic mechanism compensates for VC over-activation) (Fig. 11-b).

To establish a causal relationship between changes shown in both sensory cortices and thalamo-cortical regulation of $\mathrm{VC}$ and $\mathrm{AC}$, paired recordings should be made in our animal model in future studies.

\section{Clinical implications}

In prolonged deafness, a cross-modal reaction over-activates neighbouring sensory cortices (particularly VC), as shown in humans (Neville et al. 1983; Campbell and Sharma 2014). In this study, we demonstrated an unstable compensation of horizontal feedbacks between sensory cortices in our animal model. We have recently communicated that anodal continuous current stimulation allows restricted over-activation of the AC (Colmenárez-Raga et al. 2019). Restricted stimulation with anodal currents (activation) in the AC may be able to rebalance the cross-modal reaction, potentially improving cortical processing after cochlear implantation. Such an approach may induce a more efficient adaptation 
of cochlear implants in adults with long-term hearing loss and help to prevent cross-modal invasion in congenital deafness. A similar analysis to that presented herein, albeit in congenital deafness animal models, should be performed in future studies.

Acknowledgments The authors would like to thank Antonio SánchezGarrido (from SICNOVA) for the graphic design and printing of the 3D mask used in the tissue extraction, Javier Herrero-Turrión for his technical assistance in the RT-qPCR protocol and Carlos Melo and Heather Fulwood for editing the manuscript.

Funding This study was supported by a grant from the Ministry of Economy and Competitiveness of the Spanish Government SAF201678898-C2-2-R and BFU2017-82375-R, and from Junta de Castilla Y León SA070P17.

\section{Compliance with ethical standards}

Conflict of interest The authors declare that they have no conflict of interest.

Research involving animals/ethical approval All applicable international, national and/or institutional guidelines for the care and use of animals were followed. All procedures performed in studies involving animals were in accordance with the ethical standards of the institution or practice at which the studies were conducted, with Spanish Royal Decree 53/2013 — Law 32/2007—and with Directive 2010/63/ EU of the European Parliament. Protocols were approved by the Ethics Committee on Animal Experimentation of the University of Salamanca (Permit Number: 2012-265).

Research involving human participants This article does not contain any studies with human participants performed by any of the authors.

Open Access This article is distributed under the terms of the Creative Commons Attribution 4.0 International License (http://creativeco mmons.org/licenses/by/4.0/), which permits unrestricted use, distribution, and reproduction in any medium, provided you give appropriate credit to the original author(s) and the source, provide a link to the Creative Commons license, and indicate if changes were made.

\section{References}

Allman BL, Keniston LP, Meredith MA (2009) Adult deafness induces somatosensory conversion of ferret auditory cortex. Proc Natl Acad Sci 106:5925-5930. https://doi.org/10.1073/pnas.08094 83106

Andersen CL, Jensen JL, Ørntoft TF (2004) Normalization of real-time quantitative reverse transcription-PCR data: a model-based variance estimation approach to identify genes suited for normalization, applied to bladder and colon cancer data sets. Cancer Res 64:5245-5250. https://doi.org/10.1158/0008-5472.CAN-04-0496

Atallah BV, Bruns W, Carandini M, Scanziani M (2012) Parvalbuminexpressing interneurons linearly transform cortical responses to visual stimuli. Neuron 73:159-170. https://doi.org/10.1016/j. neuron.2011.12.013
Bardera A, Boada I, Feixas M, Sbert M (2009) Image segmentation using excess entropy. J Signal Process Syst 54:205-214. https:// doi.org/10.1007/s11265-008-0194-6

Bartel DP, Sheng M, Lau LF, Greenberg ME (1989) Growth factors and membrane depolarization activate distinct programs of early response gene expression: dissociation of fos and jun induction. Genes Dev 3:304-313. https://doi.org/10.1101/gad.3.3.304

Bizley JK, Nodal FR, Bajo VM et al (2007) Physiological and anatomical evidence for multisensory interactions in auditory cortex. Cereb Cortex 17:2172-2189. https://doi.org/10.1093/cerco $\mathrm{r} / \mathrm{bhl} 128$

Bramham CR, Worley PF, Moore MJ, Guzowski JF (2008) The immediate early gene Arc/Arg3.1: regulation, mechanisms, and function. J Neurosci 28:11760-11767. https://doi.org/10.1523/JNEUR OSCI.3864-08.2008

Bucurenciu I, Kulik A, Schwaller B et al (2008) Nanodomain coupling between $\mathrm{Ca}^{2+}$ channels and $\mathrm{Ca}^{2+}$ sensors promotes fast and efficient transmitter release at a cortical GABAergic synapse. Neuron 57:536-545. https://doi.org/10.1016/j.neuron.2007.12.026

Burns MJ, Nixon GJ, Foy CA, Harris N (2005) Standardisation of data from real-time quantitative PCR methods - evaluation of outliers and comparison of calibration curves. BMC Biotechnol 5:1-13. https://doi.org/10.1186/1472-6750-5-31

Campbell J, Sharma A (2014) Cross-modal re-organization in adults with early stage hearing loss. PLoS One 9:e90594. https://doi. org/10.1371/journal.pone.0090594

Celio MR (1986) Parvalbumin in most gamma-aminobutyric acidcontaining neurons of the rat cerebral cortex. Science 231:995997. https://doi.org/10.1126/science.3945815

Celio MR (1990) Calbindin D-28k and parvalbumin in the rat nervous system. Neuroscience 35:375-475. https://doi. org/10.1016/0306-4522(90)90091-H

Chard PS, Bleakman D, Christakos S et al (1993) Calcium buffering properties of calbindin D28k and parvalbumin in rat sensory neurones. J Physiol 472:341-357. https://doi.org/10.1113/jphys iol.1993.sp019950

Colmenárez-Raga AC, Díaz I, Pernia M, Pérez-González D, Delgado-García JM, Carro J, Plaza I, Merchán MA (2019) Reversible functional changes evoked by anodal epidural direct current electrical stimulation of the rat auditory cortex. Front Neurosci 13:356. https://doi.org/10.3389/fnins.2019.00356

Creel D, Dustman RE, Beck EC (1974) Intensity of flash illumination and the visually evoked potential of rats, guinea pigs and rats. Vision Res 14:725-729. https://doi.org/10.1016/00426989(74)90070-4

Duthey B, Caudron S, Perroy J et al (2002) A single subunit (GB2) is required for G-protein activation by the heterodimeric GABAB receptor. J Biol Chem 277:3236-3241. https://doi.org/10.1074/ jbc.M108900200

Finney EM, Fine I, Dobkins KR (2001) Visual stimuli activate auditory cortex in the deaf. Nat Neurosci 4:1171-1173. https://doi. org/10.1038/nn763

Firzlaff U, Schuller G (2001) Motion processing in the auditory cortex of the rufous horseshoe bat: role of GABAergic inhibition. Eur J Neurosci 14:1687-1701. https://doi.org/10.1046/j.0953816x.2001.01797.x

Fleige S, Walf V, Huch S et al (2006) Comparison of relative mRNA quantification models and the impact of RNA integrity in quantitative real-time RT-PCR. Biotechnol Lett 28:1601-1613. https ://doi.org/10.1007/s10529-006-9127-2

Goel A, Jiang B, Xu LW et al (2006) Cross-modal regulation of synaptic AMPA receptors in primary sensory cortices by visual experience. Nat Neurosci 9:1001-1003. https://doi.org/10.1038/ nn 1725 
Greenberg ME, Ziff EB, Greene LA (1986) Stimulation of neuronal acetylcholine receptors induces rapid gene transcription. Science 234:80-83. https://doi.org/10.1126/science.3749894

Gull SF, Skilling J (1984) Maximum entropy method in image processing. IEE Proc F Commun Radar Signal Process 131:646-659. https://doi.org/10.1049/ip-f-1.1984.0099

Hannan S, Wilkins ME, Dehghani-Tafti E et al (2011) $\gamma$-aminobutyric acid type $B(G A B A B)$ receptor internalization is regulated by the R2 subunit. J Biol Chem 286:24324-24335. https://doi. org/10.1074/jbc.M111.220814

Hendry SH, Jones EG, DeFelipe J et al (1984) Neuropeptide-containing neurons of the cerebral cortex are also GABAergic. Proc Natl Acad Sci 81:6526-6530. https://doi.org/10.1073/pnas.81.20.6526

Hudnell HK, Boyes WK, Otto DA (1990) Rat and human visual-evoked potentials recorded under comparable conditions: a preliminary analysis to address the issue of predicting human neurotoxic effects from rat data. Neurotoxicol Teratol 12:391-398. https:// doi.org/10.1016/0892-0362(90)90059-L

Ibrahim LA, Mesik L, Ji X et al (2016) Cross-modality sharpening of visual cortical processing through layer-1-mediated inhibition and disinhibition. Neuron 89:1031-1045. https://doi.org/10.1016/j. neuron.2016.01.027

Joo JY, Schaukowitch K, Farbiak L et al (2016) Stimulus-specific combinatorial functionality of neuronal c-fos enhancers. Nat Neurosci 19:75-83. https://doi.org/10.1038/nn.4170

Kawaguchi Y (1993) Groupings of nonpyramidal and pyramidal cells with specific physiological and morphological characteristics in rat frontal cortex. J Neurophysiol 69:416-431. https://doi. org/10.1152/jn.1993.69.2.416

Kawaguchi Y, Kubota Y (1993) Correlation of physiological subgroupings of nonpyramidal cells with parvalbumin- and calbindinD28k-immunoreactive neurons in layer $\mathrm{V}$ of rat frontal cortex. J Neurophysiol 70:387-396. https://doi.org/10.1152/ jn.1993.70.1.387

Kawaguchi Y, Kubota Y (1997) GABAergic cell subtypes and their synaptic connections in rat frontal cortex. Cereb Cortex 7:476486. https://doi.org/10.1093/cercor/7.6.476

Kharazia VN, Weinberg RJ (1994) Glutamate in thalamic fibers terminating in layer IV of primary sensory cortex. J Neurosci 14:6021-6032. https://doi.org/10.1523/JNEUR OSCI.14-10-06021

Kittler JT, Moss SJ (2003) Modulation of GABAAreceptor activity by phosphorylation and receptor trafficking: implications for the efficacy of synaptic inhibition. Curr Opin Neurobiol 13:341-347. https://doi.org/10.1016/S0959-4388(03)00064-3

Kittler JT, Chen G, Honing S et al (2005) Phospho-dependent binding of the clathrin AP2 adaptor complex to GABAA receptors regulates the efficacy of inhibitory synaptic transmission. Proc Natl Acad Sci 102:14871-14876. https://doi.org/10.1073/ pnas.0506653102

Kok MA, Chabot N, Lomber SG (2014) Cross-modal reorganization of cortical afferents to dorsal auditory cortex following earlyand late-onset deafness. J Comp Neurol 522:654-675. https:// doi.org/10.1002/cne.23439

Kotak VC, Fujisawa S, Lee FA et al (2005) Hearing loss raises excitability in the auditory cortex. J Neurosci 25:3908-3918. https:// doi.org/10.1523/JNEUROSCI.5169-04.2005

Lee S, Hjerling-Leffler J, Zagha E et al (2010) The largest group of superficial neocortical GABAergic interneurons expresses ionotropic serotonin receptors. J Neurosci 30:16796-16808. https:// doi.org/10.1523/JNEUROSCI.1869-10.2010

Livak KJ, Schmittgen TD (2001) Analysis of relative gene expression data using real-time quantitative PCR and the $2^{-\Delta \Delta \mathrm{T}}$ method. Methods 25:402-408. https://doi.org/10.1006/meth.2001.1262
Lyford GL, Yamagata K, Kaufmann WE et al (1995) Arc, a growth factor and activity-regulated gene, encodes a novel cytoskeleton-associated protein that is enriched in neuronal dendrites. Neuron 14:433-445. https://doi.org/10.1016/08966273(95)90299-6

Maier PJ, Marin I, Grampp T et al (2010) Sustained glutamate receptor activation down-regulates $\mathrm{GABAB}$ receptors by shifting the balance from recycling to lysosomal degradation. J Biol Chem 285:35606-35614. https://doi.org/10.1074/jbc.M110.142406

Makowiecki K, Garrett A, Clark V et al (2015) Reliability of VEP recordings using chronically implanted screw electrodes in mice. Transl Vis Sci Technol 4:15. https://doi.org/10.1167/ tvst.4.2.15

Margeta-Mitrovic M, Jan YN, Jan LY (2001) Function of GB1 and GB2 subunits in $\mathrm{G}$ protein coupling of GABAB receptors. Proc Natl Acad Sci 98:14649-14654. https://doi.org/10.1073/ pnas. 251554498

Meredith MA, Lomber SG (2011) Somatosensory and visual crossmodal plasticity in the anterior auditory field of early-deaf cats. Hear Res 280:38-47. https://doi.org/10.1016/j.heare s.2011.02.004

Morgan JI, Curran T (1988) Calcium as a modulator of the immediate-early gene cascade in neurons. Cell Calcium 9:303-311. https://doi.org/10.1016/0143-4160(88)90011-5

Neville HJ, Schmidt A, Kutas M (1983) Altered visual-evoked potentials in congenitally deaf adults. Brain Res 266:127-132. https ://doi.org/10.1016/0006-8993(83)91314-8

Paperna T, Malach R (1991) Patterns of sensory intermodality relationships in the cerebral cortex of the rat. J Comp Neurol 308:432-456. https://doi.org/10.1002/cne.903080310

Paxinos G (2004) The rat nervous system. Australia, Sydney

Paxinos G, Watson C (2005) The rat brain in stereotaxic coordinates. San Diego, USA

Pérez-Otaño I, Ehlers MD (2005) Homeostatic plasticity and NMDA receptor trafficking. Trends Neurosci 28:229-238. https://doi. org/10.1016/j.tins.2005.03.004

Pernia M, Estevez S, Poveda C et al (2017) c-Fos and Arc/Arg3.1 expression in auditory and visual cortices after hearing loss: evidence of sensory crossmodal reorganization in adult rats. J Comp Neurol 525:2677-2689. https://doi.org/10.1002/ cne. 24233

Petrus E, Isaiah A, Jones AP et al (2014) Cross-modal induction of thalamocortical potentiation leads to enhanced information processing in the auditory cortex. Neuron 81:664-673. https:// doi.org/10.1016/j.neuron.2013.11.023

Popelár J, Syka J, Berndt H (1987) Effect of noise on auditory evoked responses in awake guinea pigs. Hear Res 26:239-247. https://doi.org/10.1016/0378-5955(87)90060-8

Qiu CX, Salvi R, Ding D, Burkard R (2000) Inner hair cell loss leads to enhanced response amplitudes in auditory cortex of unanesthetized chinchillas: evidence for increased system gain. Hear Res 139:153-171. https://doi.org/10.1016/S0378 -5955(99)00171-9

Rannals MD, Kapur J (2011) Homeostatic strengthening of inhibitory synapses is mediated by the accumulation of GABAA receptors. J Neurosci 31:17701-17712. https://doi.org/10.1523/ jneurosci.4476-11.2011

Rial Verde EM, Lee-Osbourne J, Worley PFF et al (2006) Increased expression of the immediate-early gene Arc/Arg3.1 reduces AMPA receptor-mediated synaptic transmission. Neuron 52:461-474. https://doi.org/10.1016/j.neuron.2006.09.031

Rudy B, Fishell G, Lee SH, Hjerling-Leffler J (2011) Three groups of interneurons account for nearly $100 \%$ of neocortical GABAergic neurons. Dev Neurobiol 71:45-61. https://doi.org/10.1002/ dneu. 20853 
Schmittgen TD, Livak KJ (2008) Analyzing real-time PCR data by the comparative $\mathrm{C}_{\mathrm{T}}$ method. Nat Protoc 3:1101-1108. https:// doi.org/10.1038/nprot.2008.73

Steward O, Wallace CS, Lyford GL, Worley PF (1998) Synaptic activation causes the mRNA for the IEG Arc to localize selectively near activated postsynaptic sites on dendrites. Neuron 21:741-751. https://doi.org/10.1016/S0896-6273(00)80591-7

Steward O, Farris S, Pirbhoy PS et al (2015) Localization and local translation of Arc/Arg3.1 mRNA at synapses: some observations and paradoxes. Front Mol Neurosci 7:1-15. https://doi. org/10.3389/fnmol.2014.00101

Tamás G, Buhl EH, Somogyi P (1997) Fast IPSPs elicited via multiple synaptic release sites by different types of GABAergic neuron in the cat visual cortex. J Physiol 500:715-738. https:// doi.org/10.1113/jphysiol.1997.sp022054

Teichert M, Bolz J (2017) Simultaneous intrinsic signal imaging of auditory and visual cortex reveals profound effects of acute hearing loss on visual processing. Neuroimage 159:459-472. https://doi.org/10.1016/j.neuroimage.2017.07.037

Teichert M, Bolz J (2018) How senses work together: cross-modal interactions between primary sensory cortices. Neural Plast 2018:1-11. https://doi.org/10.1155/2018/5380921
Tremere L, Hicks TP, Rasmusson DD (2001) Expansion of receptive fields in raccoon somatosensory cortex in vivo by GABA A receptor antagonism: implications for cortical reorganization. Exp Brain Res 136:447-455. https://doi.org/10.1007/s0022 10000612

Tropea D, Kreiman G, Lyckman A et al (2006) Gene expression changes and molecular pathways mediating activity-dependent plasticity in visual cortex. Nat Neurosci 9:660-668. https://doi. org/10.1038/nn1689

Turrigiano GG, Leslie KR, Desai NS et al (1998) Activity-dependent scaling of quantal amplitude in neocortical neurons. Nature 391:892-896. https://doi.org/10.1038/36103

Wall MJ, Corrêa SAL (2018) The mechanistic link between Arc/Arg3.1 expression and AMPA receptor endocytosis. Semin Cell Dev Biol 77:17-24. https://doi.org/10.1016/j.semcdb.2017.09.005

Publisher's Note Springer Nature remains neutral with regard to jurisdictional claims in published maps and institutional affiliations. 